\title{
5 Ergebnisse der empirischen Forschung
}

Monokausale Erklärungsansätze, die Amoktaten auf eine einzige Ursache zurückführen wollen, scheitern bei der Erklärung dieses Phänomens. Während früher ein Amoklauf als direkte Folge einer individuellen psychischen Störung angesehen wurde, gilt diese Erklärung heute als widerlegt. Vielmehr wird angenommen, dass Voraussetzungen des sozialen Umfelds mit Voraussetzungen in der Persönlichkeit des Amokläufers zusammenwirken.

Wie schon erwähnt, besteht ein Konflikt in der Forschungsszene, verbindliche Definitionen und Abgrenzungen für das Phänomen Amoktat zu finden. Die meisten empirischen Befunde stützen sich nicht auf die Klassifikation im Sinne des ICD-10, sondern auf eigene Kriterien. Die Empirik zu Amoktaten wird auch deshalb als ungenügend bewertet, weil es eine niedrige Prävalenz gibt und erhebliche Unterschiede bei den Fallkonstellationen auftauchen. So nimmt man an, dass über 50\% der Täter mit psychischen Störungen zu kämpfen hatten, ein geringerer Prozentsatz aber eine klassische psychiatrische Vergangenheit besitzt.

\subsection{Die sieben W-Fragen}

Um die verschiedenen Modelle, Theorien, Sichtweisen, Erfahrungswerte in einer übersichtlichen Struktur darstellen zu können, werden im Folgenden die „Sieben W-Fragen“ nach Imbusch (2002) zur Gliederung und zur Bestimmung von gewalttätigen Interaktionen benutzt: 
1. „Wer übte Gewalt aus und wer ist in der Gefahr, Gewalt auszuüben?“ Frage nach dem Täter und nach potenziellen Tätern.

2. „Was geschieht, wenn Gewalt ausgeübt wird?“ Frage nach Tatabläufen.

3. „Wie wird Gewalt ausgeübt?“ Frage nach den eingesetzten Mitteln.

4. „Wem gilt die Gewalt?“ Frage nach den Opfern.

5. „Warum wird Cewalt ausgeübt?“ Frage nach den Ursachen.

6. „Wozu wird Gewalt ausgeübt?“ Frage nach Zielen und Motiven

7. „Weshalb wird Gewalt ausgeübt?“ Frage nach den Rechtfertigungsmustern.

Die psychischen Probleme vieler aggressiver Jugendlicher können im psychiatrischen Sinne als seit der frühen Jugend bestehende „Störungen des Sozialverhaltens" diagnostisch eingeordnet werden. Unter dem Einfluss mangelnder erzieherischer Steuerung und Vernachlässigung kann sich bei dieser Personengruppe eine „antisoziale Persönlichkeit“ herausbilden. Dem gegenüber sind sogenannte Amokläufer sehr viel stärker als ,Jugendliche in einer adoleszenztypischen Krise“ zu beschreiben, da sie bestimmte Entwicklungsaufgaben wie die realistische Einschätzung ihrer Möglichkeiten oder der erste Kontakt mit möglichen Sexualpartnern nicht bewältigen und sich häufig gedemütigt fühlen.

Die wichtigsten Diagnosen und Klassifikationsversuche, die im Zusammenhang mit aggressiven und gewalttätigen Verhaltensweisen stehen, sind in ICD-10 zusammengestellt.

\section{Diagnosen und Klassifikationsversuche nach ICD-10}

Störung des Sozialverhaltens bei fehlenden sozialen Bindungen (F 91.1) mit oppositionellem, aufsässigem Verhalten (F 91.3).

- Kombinierte Störung des Sozialverhaltens und der Emotionen (F 92.8)

- Bindungsstörung mit Enthemmung (ICD-10 F 94.2.)

- Beginnende emotional-instabile Persönlichkeitsstörung vom impulsiven Typ (F 60. 3)

- ADHS (F 90.1)

- Alkohol- und Drogen-Abusus (F 19.2)

- Posttraumatische Belastungsstörungen ( $\mathrm{F} 43.1 \mathrm{bzw}$. Anpassungsstörungen F 43.2)

\section{Dissoziale Persönlichkeitsstörung (F 60.2)}

- Unbeteiligtsein gegenüber den Gefühlen anderer, Affektlosigkeit

- Deutliche und andauernde Verantwortungslosigkeit

- Unfähigkeit zum Erleben von Schuldbewusstsein

- Erhebliche Impulsivität, reizbares, aggressives Verhalten

- Übermäßige Abhängigkeit von anderen

- Projektion eigener, bei sich selbst nicht akzeptierter Gefühle in andere Menschen 


\subsubsection{Entwicklungsmodell für Störungen des Sozialverhaltens}

Schon in der Phase des Vorschulalters können Kinder ein schwieriges Temperament, Hyperaktivität, offene Aggression, oppositionell-aufsässiges Verhalten, defizitäre Sozialbeziehungen und Lernstörungen zeigen. In der Phase des Jugendalters entwickeln sie dann verdeckte Störungen des Sozialverhaltens, geraten in Gruppen dissozialer Jugendlicher, neigen zu Delinquenz und können eine antisoziale Persönlichkeit entwickeln.

Bei den Klassifikationsschemata ICD-1o und das DSM-IV-TR handelt es sich um eine „kategoriale Diagnostik“ im Gegensatz zu einer „dimensionalen Diagnostik“ wie Autismus-Spektrum-Störung mit fließenden Übergängen. Dadurch können subklinische Ausprägungen und Normvarianten besser erfasst werden.

Mit Hilfe des CBCL-Fragebogens (Elternfragebogen über das Verhalten von Kindern und Jugendlichen [CBCL/4-18]) werden zwei Dimensionen erfasst:

- externalisierende Störungen mit aggressiven, expansiven und dissozialen Verhaltensweisen,

v internalisierende Störungen mit ängstlich-depressivem Verhalten, sozialem Rückzug und körperlichen Beschwerden.

Da bei aggressiven Jugendlichen oft auch affektive Störungen (severe mood dyregulation) vorhanden sind, aber meist nicht sichtbar werden, können sie mit dem Instrumentarium des CBCL-Fragebogens zusätzlich erfasst werden.

In der funktionellen Magnetresonanztomographie (fMRT) findet man bei Patienten mit einer Sozialstörung und solchen mit zusätzlicher Störung der Affektregulation deutliche Unterschiede bei Vorgabe negativer Bilder. Insofern können sich auch unterschiedliche Profile über folgende acht Subskalen hinweg zeigen:

1. sozialer Rückzug

2. körperliche Beschwerden

3. Angst und Depressivität

4. dissoziales Verhalten

5. aggressives Verhalten

6. soziale Probleme

7. schizoid und zwanghaftes Verhalten

8. Aufmerksamkeitsstörung.

Die Kenntnis dieser Risikoprofile ist im Hinblick auf die Entwicklung späterer psychopathologischer Krankheitsbilder wie Suizidalität, Substanzmissbrauch, Depressionen, Borderline-Persönlichkeitsstörung, adultes ADHS von Bedeutung.

Die Phase der Adoleszenz wird als zentral für die Selbstentwicklung angesehen. Dabei stellen sowohl hohe Risikobereitschaft, Neigung zur Grandiosität, exhibitionistische Fantasien und Machtfantasien, welche auch die häufig adoleszentäre Werbesymbolik prägen, ein integriertes Selbst und integrierte Ob- 
jekte nicht in Frage. Der Wunsch nach einer Beziehung zu einem Mädchen belastet die meisten potenziellen Täter mit einem Gefühl der Nicht-Erreichbarkeit von Frauen. Dieser „Fata-Morgana-Effekt“ führt zu einer erheblichen Frustrierung verschiedener Triebimpulse.

Pubertäts- und Adoleszenzkrisen können mit Eigen- oder Fremdgefährdungen verbunden sein. Werden in der Adoleszenz ausgeprägte Erfahrungen mit Gewalt gemacht, ob als Opfer oder Täter, kann das neben soziale auch langfristige psychobiologische Folgen haben, die sich ungünstig auf die Fähigkeit auswirken, Stressbelastungen zu bewältigen. Die Möglichkeit eines Scheiterns in einer wichtigen, Weichen stellenden Situation ist immer gegeben und muss ernst genommen werden. Ernst nehmen heißt, jemanden beachten, ihn ansprechen, die Dinge nicht treiben lassen, sich seiner Verantwortung nicht entledigen, sondern notfalls energisch intervenieren. Je stärker das Ausmaß der Gewalt ist, desto ausgeprägter sind die Folgeprobleme. Eine frühe Bereitschaft zu körperlicher Gewalt sagt spätere Gewalt voraus. Darum müssen Risikofaktoren bei Gewaltexplosionen und Gewaltausübung frühzeitig erkannt werden, um präventive Maßnahmen ergreifen zu können.

Moffits (1993) Verlaufsstudien zu antisozialen Entwicklungen zeigen, dass es vorübergehende antisoziale Tendenzen in der Adoleszenz gibt, die rechtfertigen, die Diagnose der antisozialen Persönlichkeit nicht vor dem 18. Lebensjahr zu stellen. Adoleszenzkrisen können sich als kurze depressive Reaktion (F 43.20), als längere depressive Reaktion ( $\mathrm{F}$ 43.21) und als gemischte Angst und depressive Reaktion zeigen (F 43.22). Auch andere Gefühle können stärker beeinträchtigt werden (F 43.23). Ganz besonders häufig sind im Jugendalter „Anpassungsstörungen mit vorwiegender Störung des Sozialverhaltens“ oder "gemischter Störung von Gefühlen und Sozialverhalten“ (F 43.24; F 43.25).

Die subjektive Schilderung von Belastungen und wahrgenommenen Lebensereignissen (life events) wie Sitzenbleiben, Verlassenwerden von der ersten Freundin, vom ersten Freund oder das Erleben weit verbreiteter Übergriffe der „Digital Natives“(Gasser 2011) durch Mobbing, Bullying, Bloßstellung im Internet durch Cyberbullying und altersinadäquate Anmache oder sexuelle Übergriffe im Internet macht deutlich, dass es zahlreiche bedrohliche Situationen gibt, die zu Anpassungsstörungen und zu Störungen der Selbstregulation führen können.

Nach Meinung von Gasser (2011) trennen Schüler nicht zwischen „Online“ und „Offline“. Schulhof und Internet können sich bei ihnen miteinander verschränken. Untersuchungen zeigen, dass die Opfer von „Cybermobbing“ auch Opfer von Mobbing im echten Leben sind. Die Anonymität im Netz reduziert zwar die Hemmschwelle, aber beim Cybermobbing " können Opfer identifiziert werden. Andererseits mobben Opfer von „Cybermobbing“ überdurchschnittlich oft wiederum andere. Sie haben nämlich gelernt, wie solche Attacken funktionieren, und schlagen in einer „Blitzableiter-Handlung“ zurück, um sich nicht länger schwach zu fühlen. 


\section{Cybermobbing muss wahrgenommen und unterbunden werden.}

\subsubsection{Modell der psychologischen Autopsie bei retrograder Betrachtung}

Um die destruktiven Fantasien von Amokläufern zu rekonstruieren, stützen sich Forscher auf Tagebucheinträge, Zeichnungen, Aufsätze oder andere kreative Auseinandersetzungen der Jugendlichen mit ihrer Innenwelt und Außenwelt. Katz (zit. nach Robertz 2004) beschäftigte sich in den USA intensiv mit Gewaltfantasien von Straftätern und beschreibt in seinem Buch „Verführungen des Verbrechens“ den Typus des „selbstgerechten Cemetzels“(righteous slaughter). Die Absicht zum mörderischen Handeln entspringt dann oft dem intensiven Willen, seine eigene Vorstellung von „allumfassender Gerechtigkeit“ durchzusetzen, gerade weil der Täter glaubt, sehr viel Ungerechtigkeit erfahren zu haben. Rationale „Kosten-Nutzen-Überlegungen“ sind ab einem bestimmten Punkt nicht mehr möglich und werden schließlich über Bord geworfen.

Robertz (2004) ist der Meinung, dass manche Amokläufer einen „Mythos“ um sich aufbauen und als „Antihelden “ in die Geschichte eingehen wollen: Wäre er erst in YouTube, sei er „unsterblich“ und könne „posthum noch eine Fan-Gemeinde um sich scharen".

Für die Äußerungen von Harris und Klebold benutzt Katz (s. Robertz 2004) die Kategorie des „Ur-Bösen“ (primordial evil), da die Täter ihr Selbstbild an einer klassischen "Gottheit“" orientieren, die nicht geliebt, sondern gefürchtet werden will. Nach Katz lebten Klebold und Harris in einer Fantasie- und Parallelwelt und entzogen sich jeglicher Kontrolle ihres sozialen Umfelds. Am Ende demonstrierten sie ihre „Allmacht“, indem sie sich zu „Herren über Leben und Tod“ aufschwangen. So schrieb Klebold ein Jahr vor dem Massaker in das Schuljahrbuch: „Meine Rache wird die eines Cottessein“. Diese Fantasien sind nach Meinung von Katz das Ergebnis eines mehrjährigen Prozesses und haben die Täter mit der Zeit so sehr vereinnahmt, dass ihre obsessiven und zwanghaften Gedankenspiele immer mehr zu destruktiven „Attraktoren“ wurden, die schließlich in die Tat umgesetzt wurden.

Gaertner (2009) schreibt in seinem Buch „Ich bin voller Hass - und das liebe ich“ über das Massaker an der Columbine-Highschool, Harris und Klebold seien zum Schluss nicht mehr für andere Menschen erreichbar gewesen, weil sie sich zu verstellen gelernt hatten. Ihren Hass wie ihre Liebe hätten sie für sich behalten, und ihre Gedanken allein Notizbüchern und Computerdateien anvertraut. Sie speicherten alles auf Videos und stellten sie ins Internet. Harris schwelgte in seinen Aufzeichnungen immer wieder in „Allmachtsfantasien“, wenn er auf „Schwarze, Ladinos und Behinderte“ schimpfte, „Nazi-Sprüche“ klopfte und/oder sich mit der Ausrottung der gesamten Menschheit beschäftigte. 
Bei der Durchsicht der Dokumente hatte Gaertner jedoch nie den Eindruck, es mit „Monstern“ zu tun zu haben. In der Öffentlichkeit gibt es jedoch immer noch Vorstellungen - oft medial bedingt - virulent, dass die Täter „verrückt“ waren und an einer Wahnerkrankung oder Psychose litten oder dass die Täter aus einer „kaputten Familie“ kamen.

\subsubsection{Leaking und Früherkennung bei drohender Tat}

Früherkennung und Gefährdungsanalyse nutzen das Phänomen des „Leaking“, d.h. dem Durchsickern von Gewaltfantasien oder dem Bekanntwerden der Planung eines Amoklaufs. Oft werden im Chat schon Hinweise für eine Tat gegeben. Wenn das „Abtauchen“ in die Fantasiewelt und in die virtuelle Welt immer wichtiger wird, vernachlässigen die potenziellen Amokläufer ihre Beziehungen zu ihrer Umwelt immer mehr. Um aber sicherzugehen, dass ihre anonymen Nachrichten auch an die Welt ankommen, senden potenzielle Amokläufer und School Shooter oft noch kurz vor ihrer Tat Nachrichten an Mitschüler und an die Presse oder stellen die Inhalte ihrer Fantasien ins Netz.

Nach den Vorstellungen potenzieller Täter darf die Ausführung der Tat nicht in beliebiger Weise stattfinden, sonder muss exakt ihrer individuell ausgestalteten Fantasie entsprechen. So schickte Cho S. ein ganzes Paket mit selbst gedrehten Videos, Fotos sowie ein mehrseitiges Schreiben an den Fernsehsender NBC. Sebastian B. versandte sein Tagebuch an mehrere Schulkameraden und schrieb in seinem Abschiedsbrief:

„Weil ich weiß, dass die ,Fascholizei‘ meine Videos, Schulhefte, Tagebücher, einfach

alles, nicht veröffentlichen will, habe ich das selbst in die Hand genommen“.

Bemerken Lehrer, Eltern oder Schulkameraden, dass sich ein Schüler intensiv destruktiven Fantasien hingibt und seine sozialen Kontakte vernachlässigt, sollten sie mit Hilfe eines geschulten Krisenteams entscheiden, wie ernst dies zu nehmen ist. Dazu gehören vor allem Lehrer, schulpsychologischer Dienst und Polizei. Sie müssen einschätzen, ob es sich um vorübergehende pubertäre Vorstellungen, Wichtigtuerei oder um Fantasien handelt, die tatsächlich umgesetzt werden sollen. Dies erfährt ein Krisenteam durch Gespräche mit dem betroffenen Schüler, seinen Angehörigen und mit Klassenkameraden. Außerdem ist abzuklären, ob der Jugendliche Zugang zu Waffen hat.

\subsection{Ermittlung des aktuellen psychischen Zustands potenzieller Täter}

Bei der Ermittlung des aktuellen psychischen Zustands eines problematischen Kindes oder Jugendlichen ist in Erfahrung zu bringen, ob sie in jüngster Zeit gravierende Kränkungen oder Verluste erlitten. So sprach Sebastian B., Emsdetten, von seiner „Schule als seinem meist gehassten Ort“. Dort erfuhr er seine 
schwersten Kränkungen. Aus diesem und ähnlichen Gründen werden Schulen oft als Tatort ausgewählt.

\section{Fallvignetten}

\section{K., ein 10 Jahre alter Junge}

Die Akutvorstellung von K. in der kinder- und jugendpsychiatrischen Klinik erfolgte in Begleitung der Mutter und seines Lehrers. K. hatte zuvor zusammen mit seiner Mutter acht Monate in einer Entzugsklinik verbracht. Diese Maßnahme wurde vorzeitig beendet, da K. im Spielzimmer der Klinik Feuer gelegt hatte. In seiner neuen Klasse kam es bald zu Streitigkeiten, verbalen und körperlichen Auseinandersetzungen mit Mitschülern.

Im Unterricht schrieb er einen Brief an die Schule mit einer Bomben- und Suizidandrohung und versteckte ihn unter seinem Tisch. Er gelangte „per Zufall“ in die Hände seines Lehrers.

Der Lehrer sagte: „K. ist ein sehr verschlossener Junge, zu dem ich bisher keinen richtigen Kontakt gefunden habe. K. erfindet oft Fantasiegeschichten und berichtet diese glaubhaft."

Nach seiner stationären Aufnahme gelang es K., sich nach anfänglichem Misstrauen gegenüber seiner Therapeutin in der Einzeltherapie zu öffnen. Er brachte seine Zeichenhefte mit Bildgeschichten mit und äußerte stolz, dass er später „Comic-Zeichner" werden möchte (s. Abb. 2).

K. berichtete, dass er sich seine Geschichten immer "sehr lebhaft vorstellen“ kann. Er zeichnete in seinen „Comics “ wiederkehrend ähnliche Figuren, denen er eigene Fantasienamen gab. Häufig stellte er zwischen den Figuren Kämpfe zwischen „Gut und Böse“ dar. Sich selbst zeichnet er meist als Heldenfigur (Punk). Für seine unterschiedlichen Gefühlszustände stellte er verschiedene Figuren dar, so eine für "Gelassenheit" und „Cool sein“, dann einen „Baummenschen für Ruhe und Sicherheit" und schließlich einen „Feuermenschen für Wut und Aggression".

Die Geschichten gestaltete er sehr realistisch, teilweise konnte er aber Realität und Geschichte kaum unterscheiden. Er äußerte seine Angst vor Halluzinationen und "für verrückt" erklärt zu werden.

Wichtig war es für inn zu wissen, ob es „normal“ sei, dass er manchmal Figuren aus seinen Geschichten vor sich sehe oder selbst mitten in einer Geschichte aufwache und sich dann wie seine Comic-Figur fühlen würde. Er äußerte, dass diese Zustände begonnen hätten, als er sieben oder acht Jahre alt war. Wenn seine Mutter Alkohol getrunken hatte, habe er sich sehr oft in sein Zimmer zurückgezogen und seine eigenen Geschichten ausgedacht. Auf die Frage, ob sich etwas an seinen Geschichten geändert habe, seit er stationär aufgenommen worden sei, gab er an, dass die Geschichten in seiner Vorstellung noch "farbiger" geworden seien. 


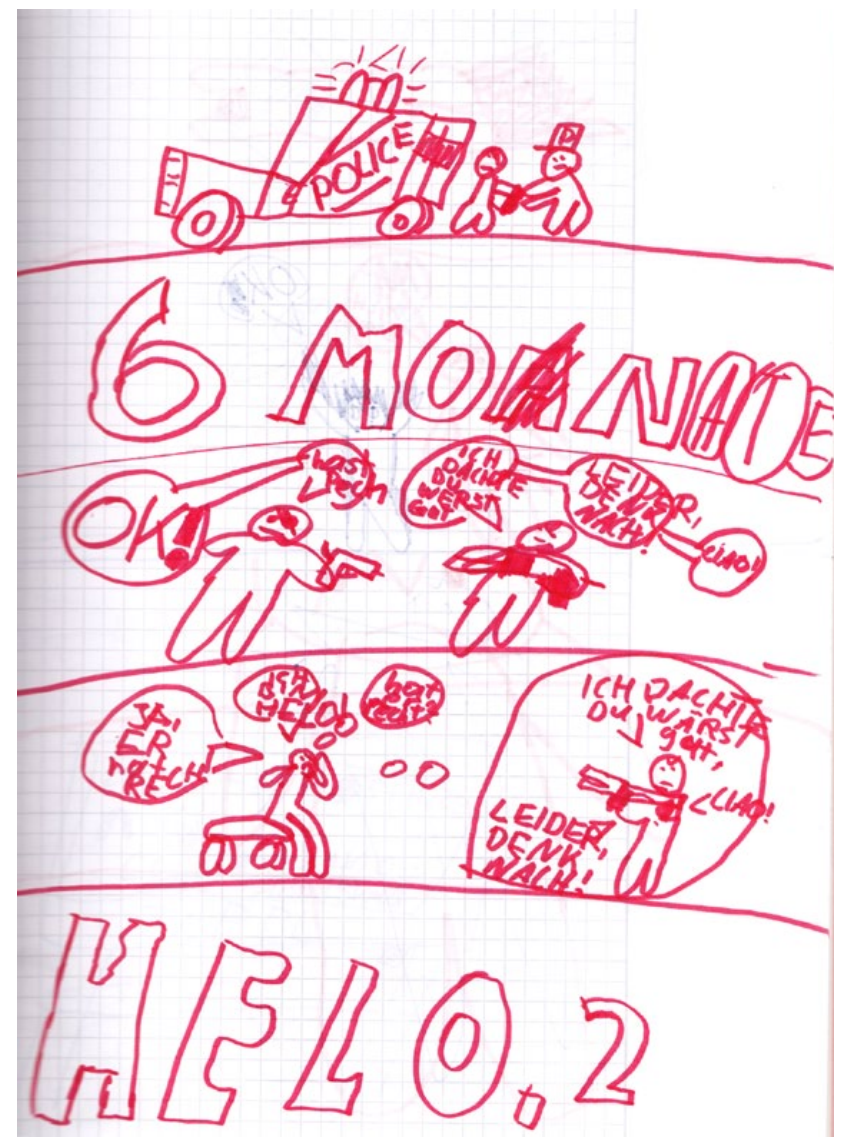

Abb. 2 Aus dem „Comic-Heft" von K.

\section{L., ein 11 Jahre altes Mädchen}

L. gab bei der Vorstellung in der Klinik an, dass sie von ihren Klassenkameraden längere Zeit gemobbt worden sei. Am Vortag der stationären Aufnahme hätten Mitschülerinnen bei ihrem Vater angerufen und dort Beschimpfungen und Beleidigungen gegen sie ausgesprochen. Sie sei daraufhin „zusammengebrochen", habe mit Selbstmord und Amoklauf gedroht.

Nach der stationären Aufnahme konnte L. sich relativ schnell von akuter Selbstund Fremdgefährdung distanzieren. Ihr ursprüngliches Verhalten wurde als Folge der starken Belastung gewertet, wobei keine Absicht einer konkreten Handlung zu erwarten war. 


\section{S., ein 17 Jahre altes Mädchen}

S. wurde nach einer Intervention des schulpsychologischen Dienstes und der Kriminalpolizei stationär aufgenommen, nachdem sie in der Schule einen Amoklauf angedroht hatte.

Im stationären Setting konnte sich S. nach kurzer Eingewöhnungszeit gut stabilisieren. Nach wenigen Tagen grenzte sie sich klar und glaubhaft von ihren Plänen eines Amoklaufs und sonstiger Selbstgefährdung ab.

Es wurde ihr eine ambulante psychotherapeutische Behandlung und die Auseinandersetzung mit den Schwerpunktthemen „Umgang mit Mobbing“ sowie „Stärkung des Selbstwertgefühls" dringend empfohlen.

\section{G., ein 18 Jahre alter Schüler}

Der Verfasser wurde von der Direktorin eines Gymnasiums in Hamm (Westf.) aufgrund von Gerüchten angesprochen, ein Amoklauf stünde bevor, den G. ausführen wolle. Durch die Hinweise eines Mitschülers, dass $G$. ein potenzieller Amoktäter sei, habe G. sich provoziert gefühlt und einigen jüngeren Schülern in einer affektiv aufgeladenen Situation Gewalt angedroht.

G. war zuvor wegen eines ähnlichen Vorfalls in einer anderen Schule stationär in der Hammer kinder- und jugendpsychiatrischen Klinik untergebracht worden. Nach Klärung der entstandenen Dynamik, einer Einschätzung seines Gewaltpotenzials und des Nicht-Vorliegens einer zielgerichteten Amokplanung sowie Stabilisierung seines Zustands und Vorbereitung auf die neue schulische Situation wurde ein Schulwechsel vollzogen. G. konnte sich in die neue Klasse gut integrieren. Das Lehrer-Kollegium war über seine Vorgeschichte informiert.

Durch Gerüchte eines früheren Schülers, $G$. habe schon einmal wegen eines Amokverdachtes die Schule wechseln müssen, entwickelte sich eine zunehmend aggressive und panikartige Stimmung. Die Lehrer konnten diese nicht mehr eingrenzen, sodass um eine ambulante Untersuchung von G., und um eine Beratung der Schulleitung gebeten wurde.

Dieser Vorfall führte dann zu einem Vortrag des Verfassers in der Schule, zu dem das Lehrerkollegium, die Eltern und die Schüler der Oberstufe eingeladen wurden, mit dem Ziel einer Versachlichung der Diskussion und einem weiterem Verbleib von $\mathrm{G}$. an dieser Schule.

\section{P., ein 15 Jahre alter Junge}

Durch den Auftrag der Staatsanwaltschaft untersuchte der Verfasser den Jungen P. nach seiner forensischen Unterbringung, weil dieser in der kinder- und jugendpsychiatrischen Klinik einen nahezu gleichaltrigen Jugendlichen gewürgt hatte. Dabei war P. gezielt in einen Gruppenraum gegangen, in dem ein Mädchen und sein späteres Opfer saßen. Er äußerte ihnen gegenüber, dass er "mal sehen möchte, wie es sei, wenn jemand stirbt", machte das Licht 
aus und ging auf sein Opfer zu, das er von hinten mit seiner rechten Hand „mit einem Kanickelfangschlag“ umklammerte, während er ihm von vorn mit der linken Hand den Hals zudrückte. Erst als sein Opfer röchelte und sich zu wehren begann, ließ er von ihm ab. In diesem Moment betrat eine Betreuerin den Gruppenraum. P. gab seine Tat sofort zu und entschuldigte sich dafür. Sein Opfer hatte massive Würgemale am Hals und musste ärztlich versorgt werden. Schäden konnten mittels CT ausgeschlossen werden.

P. äußerte, er habe ab einem bestimmten Punkt seine Kontrolle verloren. Er habe sich am Wochenende durch die Mitarbeiter der Station ungerecht behandelt gefühlt, in sich den ganzen Tag über massive aggressive Gefühle und Gewaltfantasien wahrgenommen. Sein Opfer, das er als "Stationstrottel“ bezeichnete, habe er schon öfters, ohne dass es im Alltag groß aufgefallen sei, mit Beleidigungen provoziert.

Schon etwa $1 \frac{1}{2}$ lahre zuvor hatte P. sich in einer kinder- und jugendpsychiatrischen Klinik wegen einer Amokdrohung befunden. Damals hatte er im Internet seinen Suizid angekündigt und eine Todesliste von Mitschülern erstellt.

P. berichtete, seine Eltern hätten sich getrennt, als er zehn Jahre alt war, wobei schon längere Zeit davor ein regelrechter "Familienkrieg“ entbrannt sei. Außerdem sei er längere Zeit von Mitschülern gemobbt worden, was zu einem Schulwechsel geführt habe. Der Schulwechsel vom Gymnasium auf eine Realschule sei für inn eine zusätzliche Kränkung gewesen. Der jetzige stationäre Aufenthalt sei der achte in einer kinder- und jugendpsychiatrischen Klinik mit zwischenzeitlichen Unterbringungen in zwei verschiedenen Wohngruppen der Jugendhilfe. Zuletzt sei er in einer Spezialeinrichtung für psychisch kranke Jugendliche mit einer jugendpsychiatrischen und psychotherapeutischen Betreuung gewesen.

Seine Eltern berichteten, dass sich P. oft „wie eine gespaltene Persönlichkeit“ verhalte.

P. beschrieb mit Hilfe des Fragebogens „Gewaltfantasien“ seine massiven fremd- und eigenaggressiven Impulse, seine ständige latente Suizidalität, seinen Hass - insbesondere auf die Eltern und frühere Mitschüler-, seine Rachegelüste und die reale Gefahr, seine destruktiven Impulse nicht mehr unter Kontrolle halten zu können. Er zeigte die typischen Symptome einer beginnenden „emotional-impulsiven Persönlichkeitsstörung vom Borderlinetyp“ (F 60.3 nach ICD-10) mit einer ausgeprägten depressiven und narzisstischen Problematik.

Sein manipulatives Verhalten und seine „Maskerade “ wurden dahingehend gedeutet, dass P. nur durch sie seine für inn unerträgliche Situation erträglicher gestalten konnte und sich vor erneuten narzisstischen Kränkungen und Scham zu schützen versuchte. Um seine grandiosen Vorstellungen aufrechterhalten zu können, setzte er neben Spaltungsprozessen, Projektionen, Idealisierungen und Entwertungen auch den Abwehrmechanismus der Verleugnung ein.

Scham ist nach Rauchfleisch (2011) ein Affekt, der als quälend und das Selbstwertgefühl unterhöhlend empfunden wird. Ein völliges Fehlen einer Über-Ich- 
Instanz lag bei P. nicht vor; eher besaß er ein strenges und sadistisches ÜberIch, das in seinen negativen Objektbeziehungen zum Tragen kam, aber auch manchmal zu für ihn unerträgliche Schuld- und Selbstunwertgefühle führte, die er projektiv in seine Umwelt verlegen und dort bekämpfen musste.

Sein eher angepasstes und devotes Verhalten während der Begutachtungssituation führte beim Begutachter zu negativen Gegenübertragungsreaktionen gegenüber P., sodass P. seine „Anpassungsstrategie “ in einem therapeutischen Prozess nicht lange würde durchhalten können. Er würde wohl den Therapeuten nicht respektieren, sondern verachten und ihn "hinters Licht" führen und damit die therapeutische Beziehung zerstören und ihn als Therapeuten entmachten wollen.

Bei der Abklärung einer möglichen „Dissoziativen Identitätsstörung“ ( $\mathrm{F} 43.8$ ) zeigten sich dissoziative Phasen mit Depersonalisations- und Derealisationserlebnissen, verschiedene „Ego-States“, die ihn in seinem Verhalten in verschiedener Weise steuerten.

Nach Nijenhuis et al. (2006) kann man von einer „primären strukturellen Dissoziation“ mit einem „emotionalen Persönlichkeitsanteil“ (EP) und einem „anscheinend normalen Persönlichkeitsanteil (ANP)“ sprechen.

Trigger für seine Persönlichkeitswechsel und für die Radikalisierung seiner Gewaltfantasien waren oft banale Feedbacks von Betreuern und Hinweise auf seine Regelverletzungen. Sie nahmen für ihn den Charakter einer massiv kränkenden und bedrohlichen Kritik an und stellten sein Selbstwertgefühl in Frage.

\subsection{Auslöser für Amokläufe und School Shootings}

Wie die Fallbeispiele belegen, gelten als Auslöser eines Amoklaufs oder School Shooting starke Frustrationen auf dem Hintergrund einer fortgeschrittenen psychosozialen Entwurzelung des Täters, wie sie bei Verlust der schulischen Integration durch Rückstufung oder durch Nicht-Versetzung, durch anhaltende Kränkungen sowie durch Konflikte in den verschiedenen Kontexten, wie dies in den Fallvignetten deutlich wird. Meist finden sich gleichzeitig mehrere Faktoren. Dabei liegen diese nicht immer unmittelbar vor dem Ereignis, sondern können bereits seit längerer Zeit bestehen. Häufig vermischen sich in dieser Phase aggressive und depressive Symptome. Meist plant der Täter den Suizid von vornherein ein.

\subsection{Psychopathologische Befunde}

Als strittige Frage gilt aber noch - wie schon eingangs am Beispiel von Tim K. dargestellt -, in welchem Ausmaß die Psychopathologie der Täter ausgeprägt war und inwieweit ihre Persönlichkeit noch als normal zu bewerten ist. Einen Typus „School Shooter“ oder ein spezifisches „Profiling“ zu generieren ist nach 
Meinung von Adler (2010) bisher aufgrund unterschiedlichster Studienergebnisse und Sichtweisen von Experten fehlgeschlagen. Auch müsse man hinsichtlich psychischer Erkrankungen zwischen prä- und postdeliktischen Diagnosen unterscheiden. Lediglich 17\% seien vor ihrer Tat als psychisch krank oder belastet eingestuft worden, aber 52\% nach ihrer Tat.

\subsubsection{Unterschiedliche Studienergebnisse}

Während Robertz (2004) nach Auswertung von sechs amerikanischen Studien, die sich auch mit Täterprofilen befassten, zu dem Ergebnis kam, dass die psychische Verfassung der jugendlichen Täter nicht von schweren psychischen Erkrankungen bestimmt gewesen ist, diagnostizierten andere Experten ausgeprägte narzisstische Persönlichkeitsstörungen, die schon bei eher banalen Anlässen zu Eskalationen geführt haben.

Hoffmann et al. (2009) fanden bei sieben Fällen von School Shootern folgende Diagnosen:

- ein Fall von Schizophrenie,

- ein Fall von Entwicklungsstörung,

- ein Fall von narzisstischer Persönlichkeitsstörung und

- vier Fälle mit Suizidgedanken.

Der Täter von Ansbach soll hypochondrisch gewesen sein. In nahezu allen Fällen werden narzisstische Eigenschaften beschrieben. Ein Prodromalstadium von Schizophrenie, die bei scheinbar unmotivierten Tötungsdelikten eine nicht unerhebliche Rolle spielt, wurde bei Tim K. (Winnenden) nicht ausgeschlossen.

Nach Hoffmann et al. (2009) hatten die Täter kein einheitliches „demographisches Profil“". Sie wiesen selten schwere psychische Störungen auf, stammten eher nicht aus „kaputten“ Elternhäusern (broken homes), waren selten ausschließlich sozial isolierte Einzelgänger und hatten ihre Taten gezielt begangen.

Die Kriminologen Fox und Levin (2001) weisen daraufhin, dass sich seltene und extreme Formen von Gewalt sehr schwer vorhersagen lassen und sich das „klassische Profiling“ hierbei nur bedingt erfolgreich anwenden lässt.

Moore et al. (2003) konnten in einer Meta-Studie über School Shootings der letzten 20 Jahre ebenfalls kein eindeutiges Profil hinsichtlich ethnischer, regionaler und sozialer Hintergründe, familiärer Verhältnisse und der Häufigkeit sozialer Kontakte herausarbeiten.

Die Kriminologin Bannenberg (2010b) kam zu dem Ergebnis, dass die Täter wahrscheinlich ,in weitaus höherem Maße psychopathologisch“ sind, als bisher angenommen. 
Pawlik (2008) fand folgende psychopathologisch relevante Befunde:

- 68\% der Täter hatten eine dokumentierte Geschichte schwerer Depressionen oder Verzweiflung.

- $71 \%$ der Täter fühlten sich gemobbt, bedroht oder verfolgt und

- 78\% hatten bereits Suizidgedanken oder Suizidversuche unternommen.

- Die Amokläufer waren in der überwiegenden Mehrzahl der Fälle Knaben oder junge Männer zwischen 11 und 21 Jahren.

Aus kinder- und jugendpsychiatrischer Sicht wird Gewaltausübung als Resultat mehrerer Faktoren aufgefasst. Es sind sowohl biologische Faktoren wie genetische Ausstattung, niedriges Geburtsgewicht, prä- und perinatale Komplikationen, hormonelle Bedingungen in Rechnung zu stellen wie auch entwicklungsabhängige, soziale und kulturelle Faktoren. Außerdem spielen interpersonelle und medienbedingte Einflüsse und belastende psychosoziale Situationen wie Vernachlässigung und Misshandlung eine Rolle.

Bereits im frühen Alter, in der Kindheit und Adoleszenz, begegnen uns verschiedene Formen aggressiven Verhaltens (Schmeck und Herpertz 2009). Bei Kindern und Adoleszenten findet man zunächst eine Störung des Sozialverhaltens mit einer Prävalenz von 6-10\% in der gesamten Bevölkerung (Lahey et al. 1999). Jungen bevorzugen mehr als Mädchen Gewalt zur Lösung von Konflikten und zeigen mehr Impulsivität und Risikoverhalten (Strüber et al. 2008).

\section{Die Hälfte der Gewalttaten wird von Jugendlichen verübt.}

Baier und Pfeifer (2011) meinen, dass die Erfahrung von innerfamiliärerer Gewalt im Kindes- und Jugendalter das Risiko, selbst gewalttätig zu werden, erhöht. Wenn Kinder und Jugendliche über längere Zeit hinweg nur Erfahrungen der Missachtung und der Ohnmacht gemacht haben, kann dies zur Folge haben, dass sie sich Achtung durch Machtausübung über andere verschaffen möchten. Die Gewaltausübung wird dann zu einer „Quelle der Anerkennung“, vor allem dann, wenn keine anderen Möglichkeiten zur Verfügung stehen. Sie verweisen auf einige Studien, die einen signifikanten Zusammenhang zwischen dem Lehrerverhalten und dem Gewaltverhalten seiner Schüler herstellen. In Schulen, in denen die „Interventionsbereitschaft“ der Lehrer bei Gewaltvorfällen ausgeprägt ist, treten seltener Gewalthandlungen auf. Ein positives Schulklima im Sinne eines „emotional supportiven Klassenraumes“ wirkt sich gewaltmindernd aus. Lehrer, die sich emotional engagieren, sind für Schüler wichtige Ansprech- und Vertrauenspersonen. Lehrer, die eine engmaschige Verhaltenskontrolle praktizieren, können nach Baier und Pfeiffer die Wirkung des Erlebens elterlicher Gewalt abschwächen. Dabei ist es ihrer Meinung nach wichtig, dass der Lehrer als Bezugsperson klare Verhaltenserwartungen formuliert, deren Einhaltung kontrolliert und gegebenenfalls auch Sanktionen ausspricht. 
Aufgrund klinischer und prognostischer Relevanz lassen sich zwei Entwicklungstypen unterscheiden.

\section{Typologie prognostischer Relevanz}

- Kinder, die bereits vor dem 10. Lebensjahr aggressives und zum Teil auch antisoziales Verhalten zeigen,

- Kinder, bei denen diese Verhaltensmuster erst später, vor allem in einer Peer-Gruppe, auftreten.

Nach den emotionalen Störungen im Kindes- und Jugendalter sind Störungen des Sozialverhaltens die zweithäufigste Diagnose in der jugendpsychiatrischen Praxis. Dabei handelt es sich um Verhaltensweisen, durch die altersgemäße Normen, Regeln und Rechte anderer beeinträchtigt werden. Ein erheblicher Verlust der „sozialen Kohäsion“ ist dann meist schon eingetreten. Entsprechend werden diese Störungen auch als „Dissozialität“ oder „antisoziales Verhalten“ bezeichnet. Der Begriff „Delinquenz“ dagegen ist ursprünglich juristischer bzw. kriminologischer Herkunft und bezieht sich auf Handlungen, die von entsprechenden Kontrollinstanzen - Gerichte, Polizei - verfolgt werden.

Simonoff et al. (2004) stellten bei vor dem 10. Lebensjahr psychisch erkrankten Kindern fest, dass sie zusätzlich zur Störung des Sozialverhaltens sehr häufig Kriterien eines ADHS zeigten. Auch bei delinquenten Jugendlichen mit einer „Borderline-Persönlichkeitsstörung“ (BPS) liegt nach Herpertz und Buchheim (2011) in 40\% der Fälle gleichzeitig eine ADHS vor. Umgekehrt entwickeln ungefähr 14\% aller Kinder mit einer ADHS eine BPS. Straffällige Mädchen zeigen in der Adoleszenz einen höheren Anteil an ADHS und BPS als straffällige Jungen (Sevecke et al. 2009). Diese Kombinationen von verschiedenen Krankheitsbildern erhöhen nach Herpertz und Buchheim (2011) die Wahrscheinlichkeit für das Auftreten dissozialen Verhaltens und ist im Kindes- und Jugendalter als prognostisch ungünstig anzusehen. Sie münden oftmals in eine „dissoziale Persönlichkeitsstörung“. Die Diagnose „antisoziale Persönlichkeitsstörung“ sollte man jedoch erst nach Abschluss der Pubertät, etwa ab dem vollendeten 18. Lebensjahr, stellen.

Aggression, Wut und Hass sind erfahrungsgemäß eher „unbeliebte“ Themen für Kinder- und Jugendpsychiater und Psychotherapeuten. Doch in vielen Störungsbildern tauchen häufig Aggressionen, Wut und Gewalthandlungen auf. 


\section{Störungsbilder in Verbindung mit Aggression und Gewalt}

- Narzisstische Persönlichkeitsstörung

- Borderline-Persönlichkeitsstörung

- Bipolare Störungen

- Psychosen

- Antisoziale Persönlichkeitsstörung

- Alkohol- und Drogenabhängigkeit

- Posttraumatische Belastungsstörungen

Eine der größten Längsschnittstudien begann 1972 in Neuseeland. Seitdem wird das Schicksal von 1.0oo Menschen, die in der Stadt Dunedin geboren sind, verfolgt. Moffitt und Caspi (zit. nach Strüber et al. 2008) untersuchten vor allem antisoziale Verhaltensweisen, die oft mit körperlicher Gewalt einhergehen. Sie unterscheiden zwei Gruppen: Bei der größeren Gruppe häufen sich antisoziale Verhaltensweisen rapide zwischen dem 13. und 15. Lebensjahr. Danach verlieren sich bei den meisten Jugendlichen solche Tendenzen wieder. Eine Minderheit zeigt jedoch bereits in der Kindheit - gelegentlich schon im Alter von fünf Jahren - antisoziales Verhalten, das bis ins Erwachsenenalter bestehen bleibt. Diese Kinder mit frühem Beginn aggressiven Verhaltens weisen insgesamt ein schwereres und vor allem grausameres Verhalten auf als die mit späterem Beginn (Moffit et al. 2002). Dabei handelt es sich fast ausschließlich um Jungen.

\section{Die Gruppe von früh auffälligen, chronischen Gewalttätern zeigt häufig diese Symptome}

- niedrige Frustrationstoleranz

- Defizite im Erlernen sozialer Regeln

- Aufmerksamkeitsprobleme

- vermindertes Einfühlungsvermögen

- mangelnde Intelligenz

- extrem impulsives Verhalten

n mangelhafte Fähigkeit, Vereinbarungen einzuhalten und wenig Zuverlässigkeit

- Schon bei geringfügiger Provokation geraten sie in Rage.

- Sie können die Folgen und Konsequenzen ihres Tuns nicht mehr überblicken.

- Sie fühlen sich bedroht, in der Annahme, dass man sie anstarrt.

Das „Psychopathy“-Konzept von Hare (2000) bezeichnet den gefühllosen, gefährlich aggressiven, egozentrischen, verantwortungslosen Kriminellen, der zur „instrumentellen und manipulativen“ Gewalt neigt. Dabei ist die Gewaltaus- 
übung zweckgerichtet. Diese Jugendlichen zeigen sehr selten affektive Reaktionen, da sie auf verstandesmäßige Bewältigungen zurückgreifen können, mit denen sie sich und andere täuschen. Sie zeigen auch kontrollierte mimische Reaktionen (Pokerface). Ihr physiologisches Erregungsniveau bleibt in erregenden Situationen niedrig. Man unterscheidet zwei Reaktionstypen.

\section{Formen von „Psychopathy“ nach Hare (2000)}

Sozialisierter Typ: instrumentalisierendes und antisoziales Verhalten in einer Gruppe von Gleichaltrigen.

- Nicht sozialisierter Typ: Unfähigkeit, mit Gleichaltrigen Bindungen einzugehen.

Unter für sie „normalen“ Bedingungen haben solche Jugendliche gelernt, sich anzupassen, indem sie Regungen des Zorns, der Wut, des Hasses und der Enttäuschung verbergen oder abspalten. Sie sind sich oft ihrer Gefühle nicht bewusst und können sie nicht artikulieren. Man sprich von Alexithymie. Oberflächlich passen sie sich den Erwartungen ihrer Bezugspersonen mimikryhaft an. Unter der besonderen Belastung, die im Verlauf einer Psychotherapie auftreten kann, brechen aber ihre üblichen „Funktionsebenen“ häufig zusammen. Selbst für Therapeuten ist es oft schwierig, zu solchen Kindern und Jugendlichen eine emotionale Beziehung herzustellen. In der Pubertät kann es zur Reaktivierung traumatischer Erfahrungen und von Gefühlen, Wut, Hass und Rache kommen. Rache und Trauma, einschließlich Demütigung und Kränkung, stehen in so enger Verbindung zueinander, dass keine dieser Erscheinungen für sich allein betrachtet werden kann (Böhm und Kaplan 2009).

Wut entsteht sekundär als Folge von Frustration oder Schmerz. Die Aufgabe von Wut besteht darin, Barrieren oder Hindernisse zur eigenen Befriedigung zu beseitigen. Manchmal möchten die Jugendlichen aber nicht nur ein Objekt beseitigen, sondern es auch leiden sehen.

Sadistische Handlungen zeigen eine Verbindung von Lust und Schmerz. Damit kann der Täter das ,verhasste Objekt“ dominieren und kontrollieren. Im Gegensatz zu der akuten, vorübergehenden und explosiblen Qualität von Zorn stellt Hass einen chronischen und stabilen Affekt dar. Der Hass gegen andere hat meist mit Selbsthass zu tun (Gruen und Weber 2001). Durch sadistisches Verhalten von Bezugspersonen, von denen jemand abhängig ist und denen er nicht entkommen kann, entwickelt der Betroffene oft Wut und Hass auf das "sadistische Objekt“. Manchmal sucht er dann nach einem völlig nichtigen Anlass, um auf andere Unbeteiligte losgehen zu können.

Neid auf andere und die damit einhergehende Gier, ihnen gleich zu sein, sind oft zusätzliche Quellen von Aggression. 
Scham führt nach Günter (2011) nicht selten zu Gewalttaten. Sie ist aber zunächst kein pathologisches Gefühl, sondern ein wichtiger Regulationsmechanismus des Selbst. Schamgefühle fordern nach Hilgers (2006) dazu heraus, eigene Konzepte wie auch die von anderen zu überprüfen. Wenn Schamaffekte in Situationen von Beschämung durch Mitschüler oder Lehrer, deren Blicken man sich nicht entziehen kann, „das Ich überschwemmen“, wird in hohem Maße das Selbstwertgefühl berührt und aggressive Impulse können ausgelöst werden. Scham ist auch Wahrnehmung von Ungleichheit, Beschämung dagegen eine Machtausübung, die Ungleichheit produziert. Scham über das minderwertige Selbst kann dann im Akt des Suizids in einen letzten „grandiosen Triumph“ über die eigene Schwäche verwandelt werden und stellt in der Fantasie vieler Patienten somit einen Akt eigener Stärke dar.

\subsubsection{Psychopathologisch relevante Krankheitsbilder}

Adler (200o) schlägt bei Amoktätern und School Shootern drei Krankheitskategorien vor:

1. Schizophrene Jugendliche bekämpfen oft aus einer Wahnvorstellung heraus irgendwelche „bösen Mächte“ oder „Invasoren aus dem All“.

2. Depressive Jugendliche bilden sich oft ein, durch eine „schandhafte“ Tat etwa die „Ehre ihrer Familie befleckt“ zu haben. Sie empfinden dadurch eine große Scham und wollen sich töten, um den ihnen Nahestehenden eine weitere Schmach zu ersparen. Bei vielen Jugendlichen liegt eine „maskierte Depression“ vor. Die daraus resultierende „Rache“ wird dann als eine Reaktion auf ungerechtfertigt empfundene Leiden verstanden.

3. In ihrer Persönlichkeit gestörte Jugendliche zeigen oftmals „narzisstische“ Anteile. Sie sind beziehungsgestört und leicht kränkbar. Andererseits sind sie bemüht, sich anzupassen. Zugleich haben sie genaue und hochstrebende Vorstellungen von sich selbst, die meist mit der Wirklichkeit nicht übereinstimmen. Ihre emotionale Instabilität zeigt sich oft in einem permanenten Wechsel zwischen narzisstische Kränkungserleben und Ohnmachtsgefühlen sowie narzisstischen Kompensationsversuchen: „Wir sind Gott.“

Diese narzisstische Anfälligkeit und Kränkung, die durch zahlreiche Demütigungen, Spott, Bedrohungen, schulischem Misserfolg, Herabwürdigungen entstanden sind, führen zu einer Flucht in Fantasiewelten von Grandiosität und Macht und zu Aufsuchen fantasieanregender Stimuli (Stimmer 1987). Heute flüchten Jugendliche oft in neue mediale Welten etwa in Ego-ShooterSpiele. Der narzisstisch auffällige Jugendliche möchte sein eigener „Impresario seiner eigenen Erscheinung“ (Baudrillard 1992) sein und entwickelt dazu durch Abwertung anderer Personen Strategien „narzisstischer Selbstwerterhöhung“ oder er neigt zu einer verzerrten Wahrnehmung vergangener Erfolgserlebnisse. Diese Jugendlichen erleiden deshalb eine Kränkung nach der anderen. Im Gegen- 
satz zu den meisten Menschen vergessen sie keine Kränkung. Die Schmach wühlt in ihnen, bis sie gegen die ihrer Meinung nach ungerechte Welt losschlagen. Diesen Tätertyp betrachtet Adler (2010) als die gefährlichste Cruppierung, weil ihre Taten am opferreichsten sind.

In dem Fallbeispiel Peter stellte der Verfasser folgende Diagnosen nach ICD-10:

- kombinierte Störung des Sozialverhaltens und der Emotionen (F 92.8)

- beginnende narzisstische Persönlichkeitsstörung (F 6o.8)

- Alkohol-Abusus (F 10.2)

- Cannabis-Abusus (F 12.2)

- exzessiver Computerkonsum (F 63.8)

\title{
Fallvignette
}

Bei Georg R., dem Schulamokläufer von Ansbach, diagnostizierte der psychiatrische Sachverständige G. E. Trott eine gravierende schizoide Persönlichkeitsstörung (Holzhaider 2010). Diese Diagnose führte zur Anerkennung einer verminderten Schuldfähigkeit.

\begin{abstract}
Knapp ein Jahr nach dem vereitelten Amoklauf in St. Augustin bei Bonn im Mai 2009 wurde die 17-jährige Täterin aufgrund eines Revisionsurteils des OLG Köln aus der JVA Köln in eine geschlossene psychiatrische Klinik verlegt, nachdem ein jugendpsychiatrischer Gutachter eine erhebliche verminderte Schuldfähigkeit aufgrund einer Persönlichkeitsstörung festgestellt hatte.
\end{abstract}

Es kann auch eine Mischung narzisstischer und schizoider Störung vorliegen. Es handelt sich dann eher um „stumme “ und schüchterne Narzissten, die sich aus emotionalen Bindungen und sozialen Kontakten zurückziehen und ein einzelgängerisches Verhalten sowie eine in sich gekehrte Zurückhaltung zeigen. Dabei besteht bei ihnen ein Unvermögen, Freude zu erleben, Gefühle auszudrücken verbunden mit einem erheblichen Mangel an Einfühlungsvermögen. Bei erlebter Herabwürdigung flüchten diese Jugendlichen ebenfalls in eine Fantasiewelt von "Grandiosität und Macht“ oder sie suchen zur Kompensation ihres Kränkungserlebnisses verstärkt fantasieanregende Stimuli auf. Gleichzeitig wollen sie ständig bewundert werden. Sie befinden sich meist aufgrund ihres unauthentischen Verhaltens in einem „Als-ob-Modus“ (Fonagy und Bateman 2006).

Nach Fonagy und Bateman (2006) kann es zu einer Regression auf einen „zweckbestimmten Modus" kommen, indem die Jugendlichen ihre Drohungen allein durch Handlungen ausdrücken wollen. Dadurch sollen die Gedanken und Gefühle der anderen beeinflusst und verändert werden. Die Jugendlichen schlagen los, um die als bedrohlich erlebte andere Person zu überwältigen und zu eliminieren.

Nach Faust (2010) leiden viele School Shooter unter klinisch bedeutsamen Angstneurosen und müssen deshalb medikamentös behandelt werden. Die 
betroffenen Jugendlichen gehen davon aus, dass sich ihre Außenseiterposition in der Schule auch in Zukunft fortsetzen wird und ziehen daraus den Schluss, vorzeitig „aus ihrem Leben verschwinden“ zu wollen, um ihre „Ruhe zu finden“. Der Rückzug aus dem sozialen Leben geschieht aus Angst, in eine Situation zu geraten, die das ohnehin geschwächte Selbstwertgefühl noch weiter destabilisieren kann. Ein bewusstes Einsetzen von Gewalt, um bestimmte Ziele zu erreichen, findet man nicht nur bei Personen mit einer narzisstischen, sondern auch bei Personen mit einer antisozialen Persönlichkeitsstörung.

Weitere Persönlichkeitseigenschaften, die bei Amoktäter und School Shooter zu finden sind, werden auch mit dem Begriff des "sensitiven Charakters" beschrieben. Hierbei zeigen die Jugendlichen eine geringe oder keine Tendenz zu „antisozialem" Verhalten. Sie sind eher durch ein internalisierendes statt durch ein externalisierendes Verhalten mit einer hohen Empfindlichkeit gegenüber Kritik, Spott und Zurückweisung mit einem Gefühl von Scham gekennzeichnet. Potenzielle Täter mit diesen Eigenschaften reagieren eher mit depressiven Verstimmungen und Suizidgedanken. Sie zeigen ebenfalls eine Abhängigkeit von Anerkennung durch andere Personen aufgrund ihres geringen Selbstwertgefühls. Sie neigen zu Grübelzwängen mit grandiosen Machtfantasien und entwickeln irrationale Glaubenssätze wie „Nur Rache kann zur Beendigung der Bedrohung beitragen.", die sich auf die Realitätswahrnehmung negativ auswirken, insbesondere wenn noch mediale Stimuli wie Ego-Shooter-Spiele und die damit verbundene „Flucht in fiktionale Welten“ hinzukommen. Es ist dann nur eine Frage der Zeit, wann die empfundene Erniedrigung in Wut umschlägt und die Gewalttat zur letzten Option wird.

Die unterschiedlichen Studien- und Analysenergebnisse sind darauf zurückzuführen, in welchem Umfang Dokumente der Täter wie Tagebuchaufzeichnungen, Verhörprotokolle oder sonstige Akten ausgewertet werden konnten. Je nach Umfang und Qualität der Dokumentation wurde ein umfassenderes und differenzierteres Bild des jeweiligen Täters möglich. Durch differenzierte Analysen von Amokläufen und Tötungsdelikten sowie durch Auswertung der Untersuchungsberichte, der psychiatrischen Gutachten und Aufzeichnungen verschiedener Täter ergibt sich folgende Tendenz:

\section{Studien- und Analyseergebnisse}

Die meisten Täter zeigen depressive suizidale Symptome (Faust 2010).

Alle Täter befanden sich vor der Tat in einer persönlichen Krise als Resultat lang anhaltender Kränkungen, Schikanen, Mobbing, Spott, Beleidigungen und mangelnder Anerkennung durch das soziale Umfeld. Längere Perioden von Demütigung, Ausgrenzung, Frustration und Ärger können nach Schmidtke et al. (2002) zu „Aufstauphänomenen“ führen, die sich dann explosiv in heftiger Aggression entladen. 
In 98\% aller Fälle gehen den Taten Konflikte voraus, die die Täter nicht bewältigen konnten.

Einige der Täter waren schlechte Schüler, hatten ein schwieriges Verhältnis zu den Eltern, zeigten Probleme im Umgang mit Mädchen. Sie hatten Zugang zu Waffen und begeisterten sich für sie und für Gewaltspiele am Computer. Sie waren meist Einzelgänger oder Außenseiter.

Die Täter stammten überwiegend aus der Mittelschicht.

School Shooting wird von den meisten Experten als eine „Exitstrategie“ bewertet, mit der Möglichkeit durch die Erniedrigung anderer die eigene Statusunsicherheit auszugleichen. Die Fragen, die sich dem Jugendpsychiater nach vollendetem School Shooting oder bei potenziellen Tätern stellen, sind:

- Bestand schon im Vorfeld der Tat eine manifeste Depression? Wie stark war sie ausgeprägt und für andere erkennbar?

- Waren die Handlungsweisen noch Ausdruck „normaler Überzeugungen“ oder schon Ausdruck „überwertiger Ideen“ oder eines „wahnhaften Geschehens"?

Stompe (2010) spricht in Erweiterung der Definition von Jaspers und Janzarik von Wahn beim Vorliegen folgender Phänomene:

- Der Wahnkranke fühlt sich aufgrund seines Weltbildes als „Zentrum der Welt“ und interpretiert alles aus der Sicht der eigenen Betroffenheit.

- Er zeigt eine Störung der Urteilsfähigkeit mit der Unfähigkeit des „Überstiegs“ mit dem Kriterium der Unbeeinflussbarkeit.

- Sein Wahn ist eine Konsequenz von „logischen Schlussfolgerungen“, an deren Überzeugungen er unbeirrt festhält.

- Er neigt aufgrund fragwürdiger Inhalte seiner Überzeugungen zu Fehlschlüssen.

- Sein Wahn pendelt zwischen den Extremen „immer gut“ oder „immer böse“.

- Andeutungen anderer Personen bezieht er fast immer auf sich.

- Sein Ich-Erleben verändert sich in dem Maße, wie sein Affekt zunehmend an Kraft verliert.

- Seine zwischenmenschlichen Beziehungen und sein Zugang zur Welt gehen ihm zunehmend verloren.

- Die Entwicklung seines Wahns führt zu einer konkreten Ausgestaltung seiner Wahnvorstellungen.

Das Phänomen „Wahn“ steht seit jeher im Zentrum des psychopathologischen Interesses, weil es sehr komplex ist. Wahn und die Halluzination sind Schlüsselmerkmale der Psychose und gehören zu den wichtigsten Erscheinungen der Schizophrenie. Wahn kann bei vielen psychopathologischen Zustandsbildern vorkommen. Eine Vielzahl von Hypothesen zu seiner Entstehung wird bis heute diskutiert Stompe (2010). Dabei sind wichtige Fragen, ob die Genese 
des Wahns durch eine Störung auf der Ebene der Affekte, auf der Ebene der Wahrnehmung oder durch kognitive Störung verursacht wird und welche Rolle die imaginativen Prozesse in der Wahnentstehung spielen.

In der frühen Phase der Wahnstimmung - gen. „Trema“ nach Conrad (2002) zeigt sich eine deutliche Isolierung und Kontaktstörung des Jugendlichen aufgrund eines wiederholten Scheiterns an der Realität. Eine angemessene Verarbeitung des eigentlichen Konflikts gelingt nicht.

Statt einer eindeutigen Psychose scheinen zahlreiche School Shooter - wie Lempp (2009) im Falle von Tim K. annahm -, unmittelbar vor ihrer Tat eine kurzzeitige Vermischung von Realität und Irrealität zu erleben, die mit herkömmlichen Kategorien der modernen psychiatrischen Klassifikationssysteme nicht fassbar sind. Dieses Erleben schreibt Lempp eher einer „überbordenden Fantasie“ als einer „klassischen psychischen Störung“ zu. Diese Fantasien können eine wahnhafte Form annehmen und im weiteren Verlauf in eine Schizophrenie einmünden. Lempp geht auch davon aus, dass sich die Täter nicht grundsätzlich von vielen anderen Jugendlichen unterscheiden. Sie würden aber ohne Halt in ihrer Familie - „unter dem Triebdruck der Pubertät“ - in einer Schule, die ohne Gnade auf Leistung pocht, durch eine ungewisse Zukunft irritiert. Indem sie sich immer mehr in „Nebenrealitäten“ verlieren, geraten sie in eine „emotionale Sackgasse“ und „Wahnwelt“. Dieser „psychotische Ausnahmezustand“ ist nach Lempp nicht allein das Ergebnis persönlichen „Wahnsinns“, sondern zugleich eine Reaktion auf das Umfeld. Nur beides zusammen, der „verwundbare“ Täter und eine „als beängstigend und brutal empfundene Mitwelt“, erzeugen das hochexplosive Gemisch, das schließlich zum Schulamoklauf führt.

Eine etwas andere Betrachtungsweise liefert in dem Fallbeispiel P. die Diagnose einer „primären Dissoziativen Identitätsstörung“ (F 44.8 nach ICD-10). Anlass dazu gaben Beobachtungen der Eltern als auch anderer Bezugspersonen an P., als ihnen in der Interaktion mit ihm ein häufiger Wechsel zwischen verschiedenen Persönlichkeitsanteilen (states) auffiel. Die Diagnose des Verfassers bezieht sich dabei auf die Theoriebildung von Nijenhuis et al. (2006, 2009). Sie beschreiben, dass Persönlichkeitsaufspaltungen mit verschiedenen „Aktionssystemen" verbunden sind. Dabei postulieren sie solche, die Funktionen im täglichen Leben kontrollieren, die sie den „anscheinend normalen Persönlichkeitsanteil“ (ANP) nennen und solche, die für das „Überleben“ essenziell sind, die sie als „emotionalen Persönlichkeitsanteil“ (EP) bezeichnen.

Erste Ergebnisse aus experimentellen Befunden bei Patienten mit einer „Dissoziativen Identitätsstörung "lassen nach Nijenhuis et. al (2006) vermuten, dass unterschiedliche Reaktionen auf traumatische Erinnerungen auf verschiedene neuroendokrinologische Faktoren zurückzuführen sind. Sie können auch durch unbewusste bedrohliche Stimuli hervorgerufen werden. Dabei besteht eine Unfähigkeit, ein traumatisches Ereignis zu integrieren. Dies führt zu einer „strukturellen Dissoziation“ in zwei unterschiedliche mentale Zustände der 
Person. Je nach Stressniveau bei sehr frühen Störungen und je nach Dauer der Traumatisierung können sich die Aktionssysteme ANP und EP noch weiter „aufspalten“ und durch sekundäre und tertiäre „Dissoziativen Identitätsstörung“ zu einer komplexen Persönlichkeitsstruktur führen. Das zeigt sich in Manifestationen parallel ablaufender mentaler Prozesse, die füreinander mehr oder weniger unzugänglich sind. Um sich dieser Komplexität anzunähern, beschreibt Fine (2006) mehrere Kategorien kognitiver Determinanten, die den pseudowahnhaften Charakter und die für Patienten mit einer „Dissoziativen Identitätsstörung " typischen kognitiven Verzerrungen erfassen, wie dichotomes Denken, selektive Abstraktion, willkürliche Schlussfolgerungen und Verzerrungen der Selbst-Wahrnehmung.

\subsubsection{Kognitive Verzerrungen}

Um „kognitive Verzerrungen“ (biases) besser zu verstehen, müssten bei potenziellen Tätern nach W. Huck in Zukunft wichtige zentrale pathogenetische Mechanismen untersucht werden, ähnlich wie dies Veckenstedt et al. (2009) bei erwachsenen paranoiden Schizophreniepatienten getan haben.

Kognitive Verzerrungen stellen sich in folgenden Aspekten dar:

1. Voreiliges Schlussfolgern. Studien zeigen nach Veckenstedt et al. (2009), dass Menschen mit „paranoider Schizophrenie“ auf der Grundlage weniger Informationen häufig ,hastige“ Entscheidungen treffen. Dieser voreilige Entscheidungsstil mit einer niedrigen Entscheidungsschwelle wird als ,jumping to conclusions bias" (JTC) bezeichnet.

Im Gegensatz dazu zieht sich bei School Shootern dieser Entscheidungsprozess in der Regel über längere Zeit hin, bis es ab einem bestimmten Punkt (point of no return) zur Tat kommt. Das klassische Experiment zur Untersuchung des voreiligen Schlussfolgerns ist der sog. „Kugeltest“. Je nach Studie trafen 40-70\% der schizophrenen Patienten bereits nach einer gezogenen Kugel eine Entscheidung, während gesunde Probanden meist einige Züge abwarteten, bevor sie eine Entscheidung fällen.

Die Studien weisen daraufhin, dass es sich bei hastigem Entscheidungsverhalten nicht um ein Defizit im schlussfolgernden Denken und Generieren von Hypothesen handelt, sondern vielmehr um eine unzureichende Sammlung von Informationen (data-gathering bias).

2. Unkorrigierbarkeit. Schizophrene Patienten zeigen die Tendenz, trotz schlüssiger Gegenargumente und Beweise des Gegenteils, an einmal bezogene, falschen Positionen festzuhalten. In der Literatur wird diese Denkweise als „bias against disconfirmatory evidence“ bezeichnet. Zur Messung der Unkorrigierbarkeit werden Geschichten aus sequentiell präsentierten Bildern oder Sätzen verwendet, die eine unerwartete Wendung nehmen und so eine Urteilskorrektur erfordern. 
3. Selbstdienlicher Attributionsstil. Unter Attributionsstil versteht man das Zuschreiben von Ursachen für das Zustandekommen verschiedener Situationen. Dabei unterscheidet man internale Attribution, bei der man sich Erfolge selbst zuschreibt und externale Attribution, bei der man die Schuld für Misserfolge eher bei anderen Menschen sucht oder sie äußeren Umständen zuweist. Beides wird als „selbstdienlicher Zuschreibungsstil“ bezeichnet und soll der Erhaltung eines gesunden Selbstwertgefühls dienen. Dieser übersteigerte „selbstdienliche Attributionsstil“ scheint also eine Schutzfunktion zu erfüllen, um Kränkungen des ohnehin niedrigen Selbstwertgefühls zu vermeiden. Menschen mit einer Schizophrenie weisen häufig einen „übersteigerten Attributionsstil“ auf. Schizophrene Menschen erleben ihre Mitmenschen als feindselig, da sie der Meinung sind, dass diese ihnen subjektive Misserfolge bescheren. Als Testverfahren zur Unterscheidung der Attributionsstile kann der „IPSAQ-Test“ (Internal Personal and Situational Attributions Questionnaire) genutzt werden.

\subsection{Ergebnisse der Suizidforschung}

Im Kontext der Suizidforschung entwickelte Henseler (1992) das Konzept der „Narzisstischen Krise“ und verwendete es zur Erklärung „temporär begrenzter suizidaler Krisen bei individualspezifischen äußeren Belastungen“. Etwa 80\% der Amokläufer und School Shooter töten sich unmittelbar nach der Tat selbst oder versuchen es zumindest. In der Regel wurden diese narzisstischen Suizidale durch Enttäuschungen oder Kränkungen aus ihren Beziehungen gerissen und gerieten in eine schwere Krise, die sie durch den Amoklauf oder das School Shooting für sich zu lösen versuchten. Damit setzten sie bewusst den Endpunkt ihrer Krise, sodass es sich bei diesem Suizid um ein geplantes Tatelement, nicht um ein spontanes Tun, handelt. Darüber hinaus wird vermutet, dass die Täter sich töteten, um eine Rückkehr in die Realität vermeiden.

Nach Ringel (1969) sollte bei potenziellen Amokläufern und School Shootern differenzialdiagnostisch stets ein „präsuizidales Syndrom“ abgeklärt werden. Es besitzt nämlich große Bedeutung in der akuten Einschätzung der Suizidalität.

\section{Das wichtigste Warnzeichen für bevorstehende Amokläufe oder School Shootings ist immer das Äußern von geplanten Suizidhandlungen!}

Das „Präsuizidale Syndrom“ besitzt folgende Merkmale, die stets als ernstzunehmende Warnzeichen zu betrachten sind (Ringel 1969):

- Einengung: Die Wahlmöglichkeiten im Leben potenzieller Täter werden immer weiter eingeengt, bis letztlich nur der Suizid als Ausweg übrig bleibt. 
- Aggressionsumkehr: Es entwickelt sich eine verstärkte und gleichzeitig gehemmte Aggression, die sich früher oder später gegen den Betroffenen selbst richtet.

- Suizidfantasien: gehen regelmäßig einer Suizidhandlung voraus. Das Gefühl, der Realität nicht gewachsen zu sein, führt zu einer Flucht in die Irrealität. Der Betroffene baut sich eine Scheinwelt auf, in der Gedanken an den Tod und schließlich an Suizid eine immer größere Rolle spielen.

Zudem beinhaltet das „Präsuizidale Syndrom“ noch folgende Merkmale:

- Beim potenziellen Täter besteht ein „Ruhe vor dem Sturm“.

- Für ihn werden die Menschen seiner Umwelt zunehmend überflüssig.

- Wenn er seinen Rückzug angetreten hat, ist er kaum noch erreichbar und wirkt sogar entspannt und gelassen.

\subsubsection{Das Phänomen des „Suicide by Cop“}

Viele Täter legen es darauf an, den ,finalen Fangschuss“ durch die Polizei zu bekommen, um nicht die letzte Verantwortung für sich selbst übernehmen zu müssen. Diese Art der Suizidalität hat dann die unbewusste Funktion, sich in einen fantasierten „Primärzustand“ zu retten, in dem es keine Beziehungskonflikte mehr gibt. Dabei wird der Tod in Kauf genommen, um weiteren Kränkungen und Beschämungen auszuweichen. Georg R., der im September 2009 bei seinem Schulamoklauf von Polizisten durch Schüsse gestoppt worden war, äußerte im April 2010 in seinem Strafprozess vor dem Landgericht Ansbach, dass er die zum Tatort geeilten Polizisten nicht töten wollte, sondern gehofft hatte, sie würden ihn erschießen.

\subsection{Unterscheidung der verschiedenen Gewaltformen}

Die empirischen Studien von Farrington und Loeber (2000) verweisen auf drei verschiedene Typen aggressiver Jugendlicher:

- Der lebenslange Typ entwickelt bereits in der frühen Kindheit Aggressionen, wobei sich die aggressive Problematik zunehmend verstärkt.

- Der zeitlich begrenzte Typ entwickelt seine Aggression in der Vor- und Grundschule, in der späten Adoleszenz oder im frühen Erwachsenenalter.

- Der späte Typ mit einer Überkontrolliertheit lässt keine Hinweise auf frühes aggressives Verhalten erkennen.

Andere Autoren wie Meloy (2006) und Wahl (2009) unterscheiden „kalte“ und „heiße“ Aggression. 


\subsubsection{Die kalte Aggression}

Die kalte Aggression benötigt in der Regel keinen unmittelbaren Auslöser. Sie wird geplant, instrumentell und zielgerichtet eingesetzt. Sie hängt von vorausgegangenem sozialem Lernen und externer Verstärkung ab. Bei der „kalten“ Aggression kommt als neue Aktionsmöglichkeit für eine Gruppe von Jugendlichen, die suizidal sind, zu einem „prolongierten Kontrollverlust“(Wahl 2009).

Meloy (2006) bezeichnet diese Form der Gewalt als „Jagdmodus“. Die Jugendlichen zeigen keine physiologische Erregung, eher emotionale Kühle, sind „cool“ im Sinne von „Rache ist ein Gefühl, das man kalt genießt“. Sie zeigen sich gesteuert, zielgerichtet und entwickeln Privatrituale wie Tragen einer besonderen Kleidung und Waffen und Symbolen. Sie fühlen sich nicht unmittelbar bedroht.

Strüber et al. (2006, 2008) sprechen allerdings nur von einer sehr kleinen Gruppe schwerer Gewalttäter, die sich durch planvolles und kaltblütiges Handeln auszeichnet.

\subsubsection{Die heiße Aggression}

Heiße Aggression ist dagegen stark affektiv besetzt und impulsiv, wobei es zu einem schnellen Kontrollverlust, ausgelöst durch aktuelle „Trigger“, kommt. Meloy (2006) bezeichnet diese Form der Gewalt als „Aktivierungsmodus“. Die Jugendlichen zeigen eine deutliche physiologische Erregung mit Erhöhung des Adrenalins, einen „fokussierten Blick“ und eine deutliche Muskelanspannung. Sie fühlen sich schnell bedroht, ihre Schmerzempfindung ist reduziert. Durch eine affektive Gewalttat versuchen sie, ihre die Bedrohung zu beenden. Sie zeigen kein zielgerichtetes Interesse für einen „Opferpool“.

\subsection{Was geschieht, wenn Gewalt ausgeübt wird?}

Oder die Frage nach den Tatbeständen und den Abläufen.

Die meisten Experten analysierten in den letzten Jahren detailliert die Abläufe des School Shootings und versuchten aus ihren Ergebnissen spezifische „Tatmerkmale“, „Tatschemata“ sowie „Stufen der zielgerichteten Gewalt“ abzuleiten.

\subsubsection{Tatmerkmale, Tatschemata und Stufen der zielgerichteten Gewalt}

Nach Robertz (2004) sind folgende „Tatmerkmale“ charakteristisch:

- Die Täter haben einen direkten Bezug zur Schule, an der sie den Amoklauf ausführen.

- Es werden Waffen mit Tötungsabsicht eingesetzt.

- Der Täter wählt seine Opfer wegen ihres „Symbolcharakters“ oder ihrer „Funktion“ als Lehrer, Schüler, Hausmeister, Sekretärin usw. aus. 
„Symbolcharakter“ haben aber nicht nur die Opfer, sondern auch der Tatort. Die Schule wird als Tatort gewählt, weil sch hier ihre Opfer aufhalten und die Schule den Tätern eine „öffentliche Bühne“ bietet, auf der sie ihre Tat zur Schau stellen können.

Robertz (2004) und Hoffmann et al. (2009) stellen folgende „Tatschemata“ dar:

- Bei der Mehrzahl der School Shootings handelt es sich um geplante und vorbereitete Taten.

- Der Entschluss zur Tat reift über einen längeren Zeitraum heran.

- Auslöser der Tat sind Kränkungen und Verluste, die vom Täter als schwerwiegend wahrgenommen werden.

- Die Ausübung der Tat erscheint dem Täter als einzige Problemlösung.

- Vorausgegangene medienwirksame Taten entfalten „Sog- und Modellwirkung“.

- An Jahrestagen mit spektakulären Amoktaten kommt es häufiger zu School Shootings.

- Amokläufe an Schulen werden meist durch Einzeltäter begangen.

- Die Täter sind in der Regel männlichen Geschlechts mit einem Altersdurchschnitt von 15,6 Jahren (Robertz 2004).

- Es werden meist Personen angegriffen, von denen sie sich gekränkt fühlen.

- Amokläufe und School Shootings werden meist nach Erstellen von Todeslisten und genauen Ablaufplänen sowie nach Verfassen und Veröffentlichen von Abschiedsbriefen oder von Videos verübt.

- Im Vorfeld der Tat sickern meist schon Informationen durch (Leaking) wie das Aussprechen von Warnungen oder die Umsetzung gewalthaltiger Fantasien in Worten, Bildern oder Geschichten.

Die Amok- und School Shooting-Forschung arbeitete typische „Phasen“ der Entwicklung eines School Shooting heraus (Bannenberg 2010a, Faust 2010, Hoffmann 2009, Robertz 2004, 2007, Scheithauer et al., 2008).

Faust (2010) beschreibt folgende Tatabläufe und Tathintergründe:

- Die Täter zeigen eine narzisstischen Vulnerabilität aufgrund massiv kränkender und sie ausgrenzender Erfahrungen, insbesondere des sozialen Ausschlusses aus Gruppen Cleichaltriger.

- Die Täter ziehen sich in eine Isolation zurück, um weiteren Kränkungen aus dem Weg zu gehen.

- Sie verbringen einen großen Teil der Zeit mit kompensatorischen Fantasien, durch die sie sich immer weiter von der Realität entfernen.

- Sie werden zu Sonderlingen, auf die Lehrer und Mitschüler ihre eigenen Aggressionen projizieren.

- Ihre kompensatorischen Fantasien entwickeln sich zu Rachefantasien, die auf konkrete Realisierungen drängen. 
Als besondere Problematik ist anzusehen, dass die Umgebung potenzieller School Shooter in der Regel alle Anzeichen ihrer Hilfsdürftigkeit übersieht. Sie braucht deren Missachtung, um sich selbst und ihr Weltbild im Sinne einer „reinen Weste“ zu stabilisieren. Sie stützt ihre Ideologie der „leistungsgerechten Schule“, indem sie die Schwierigkeiten der potenziellen Täter für „,selbstverschuldet" ansieht. Aus Rache inszenieren dann School Shooter ihren ,triumphalen Moment", indem sie ihren sozialen Ausschluss durch den Tod ihre Peiniger und den damit verbundenen irreversiblen Ausschluss aus der Gemeinschaft bestrafen. Gleichzeitig stellt die Tat als Flucht aus der eigenen Verantwortung und als Selbstbestrafung als ein „irritierendes moralisches Gemenge“ dar (Faust 2010).

Im Vorfeld beschäftigten sich die School Shooter mit den Taten ihrer Vorgänger. Sie lernen ihre eigene „Dramaturgien“ in den Medien kennen und versuchen sie im Sinne einer Selbstjustiz noch zu überbieten.

Robertz (2004, 2007) und Hoffman et al. (2009) beschreiben ähnliche Stufen und Phasen der zielgerichteten Gewalt. Hoffmann (zitiert nach Donner 2011) stellte auf einem Kongress in Berlin Ende 2010 dar, dass von der Idee bis zur Tat meist Monate, häufig auch Jahre vergehen können, wobei diese Stufen und Phasen einem erstaunlich homogenen Verhaltensmuster folgen.

\section{Tatvorfeld}

Es ist in der Zwischenzeit gesicherte Erkenntnis, dass kein Amoklauf aus ,heiterem Himmel" geschieht. Vielmehr handelt es sich um lange geplante Gewalttaten, die aus "übersteigertem Hass" und „ausgeprägten Rachefantasien“ resultieren.

Bei dem Täter liegt immer eine spezielle Problemlage vor. Ein zentraler psychischer Faktor ist in der Regel eine tiefe Kränkung, oft ausgelöst durch zurückgewiesene Zuneigung, durch Spott von Mitschülern oder durch ernsthafte Konflikte mit Lehrern oder Schulleitung.

\section{Bei School Shooter gibt es stets Hinweise auf ein erlittenes und erleb- tes Unrecht!}

Aufgrund seines Wunsches nach Rache zeigt sich der potenzielle Täter als „entsicherte Waffe“ (Hoffmann zit. nach Donner 2011).

\section{Rückzug in die Fantasie}

Der Täter beschäftigt sich zunehmend damit, ob eine Gewalttat eine Option für seine Rache sein kann. Aufgrund der erlebten Zurückweisung reagieren die potenziellen Täter mit einem Rückzug in ihre Fantasiewelt, in der sie ihre Vorstellung von Macht und Gewalt ausleben können. Macht- und Rachefan- 
tasien vermischen sich mit der Realität immer mehr. Die „geheime innere Welt“ mit ihrem Kontroll- und Dominanzbedürfnis wird weiter ausgebaut. Die Beschäftigung damit ist nach Hoffmann (2009) und Robertz (2004, 2009) oft besser zu erkennen als die eigentliche Planung.

Die Täter interessieren sich verstärkt für Jahrestage, die mit früheren Amoktaten in Verbindung stehen. Es kommt zu einer verstärkten Identifikation mit anderen Gewalttätern und zu Andeutungen ihrer geplanten Taten, frühes Leaking, weshalb Warnhinweise der Täter besonders ernst genommen werden müssen (Donner 2011).

In jeder Gerichtsakte über Gewalt an Berliner Schulen aus den vergangenen zehn Jahren stieß Scheithauer (zitiert nach Donner 2011) auf frühe Anzeichen, die im Umfeld des Täters aufgefallen waren. Der potenzielle Täter machte auch meist mehr oder weniger offene, vage oder „kryptische“ Bemerkungen über Rache.

Zur Illustration dient folgende Fallvignette über Florian K., Schulamokläufer von Ludwigshafen 2010.

\section{Fallvignette (Donner 2011)}

„Die Polizei wird auf Florian K. aufmerksam, als der 23-ährige einen Amoklauf an seiner ehemaligen Berufsschule in Ludwigshafen ankündigt, verbunden mit einem Todesdatum. Unter einem Decknamen stellte er selbst gedrehte Waffenvideos ins Netz. Doch bei einem Hausbesuch wimmelt er die Beamten ab ,Alles sei nur ein Scherz .... Hätte man sich in seinem Zimmer umgesehen, wären dreißig Schreckschusswaffen, eine Armbrust und mehrere Kampfmesser gefunden worden. Drei Jahre lang hatte er seine Taten geplant. In einem Tagebuch beschrieb er ausgiebig seine Gewaltfantasien. Auf seinem Computer fand die Polizei nach der Tat Daten, die zeigen, wie intensiv sich Florian K. mit früheren Amokläufen in Schulen beschäftigt hatte. Vier Lehrer standen auf seiner Todesliste. Am 18.2. 2010 erstach Florian K. einen seiner ehemaligen Pädagogen an der Schule. Ohne jeden Widerstand ließ er sich kurz darauf festnehmen“.

\section{Planungsphase}

Die meisten Täter veröffentlichen in unterschiedlichen Formen, wie sie ihre Vorstellungen von der Tat umsetzen können. Manchmal unternehmen sie ungewöhnliche Kontaktversuche und versuchen ihre „Kumpels“ einzubinden.

Von einem „mittleren Leaking“ spricht man, wenn der Täter seine spezifische Todesliste erstellt. Er kundschaftet die räumlichen Bedingungen der Schule aus und fertigt Zeichnungen von Schulgebäuden an.

Im Fallbeispiel Peter befanden sich in seinem „Opferpool“ mehrere Lehrer und Mitschüler, von denen er sich gedemütigt und gemobbt fühlte, sowie ein für ihn „unerreichbares“ Mädchen. 
Nach Gaertner (2009) sind Harris und Klebold in der Planungsphase einem „Programm der totalen Gefühlsabtötung“ gefolgt. Alles, was sie nun taten, war einer bewussten Entscheidung entsprungen, die sie mit allen Konsequenzen tragen wollten. Zu diesem Zeitpunkt hatten sie jeden anderen Ausweg abgelehnt und waren „aufeine Bahn eingeschwenkt“, auf der sie nur noch den Tod im Blick hatten.

\section{Ab der Planungsphase besteht für das Krisenteam einer Schule Zeit- und Handlungsdruck!}

\section{Vorbereitungsphase}

Die Täter beschäftigen sich damit, was sie am Tattag anziehen werden, z.B. den „richtigen“ Trenchcoat oder Maske und woher sie ihre Waffen (Gewehr, Messer, Axt, Samurai-Schwerter etc.) bekommen können.

Sie beschäftigen sich mit Transportfragen und mit Abschiedshandlungen und „privaten Ritualen“.

Von einem „späten Leaking“ spricht man, wenn die Täter mehr oder weniger deutlich Warnungen oder Ankündigungen an bestimmte Personen geben, damit diese nicht zur Schule gehen sollen. Die Täter verschenken ihre persönlichen Gegenstände.

Nachdem sie nun ihren endgültigen Entschluss zur Ausübung gefasst haben, gibt es für sie keinen Rückzug und keine Alternativen mehr. Sie verändern nicht nur ihr Äußeres, sondern manchmal sogar ihre Art zu sprechen. In einigen Fällen wurde sogar ein konkretes Tatdatum benannt.

Die Täter zeigen nun die klassischen Symptome eines „Präsuizidalen Syndroms“ (Ringel 1969), weil sie eine für sie selbst eindeutige Lösung als „Ausweg“ gefunden haben.

\section{Bei Übung mit Waffen ist eindeutig Handeln angesagt!}

\section{Vorsto $\beta$}

Die Täter ziehen sich im Auto oder in der Toilette der Schule um.

\section{Angriff}

Es kommt zu verschiedenen Annäherungen unter Vorwand, verdeckt oder offensiv an die Klassen-, Lehrer- und Sekretariatsräume. 


\section{Ein Frühwarnsystem muss ein qualifiziertes Wahrnehmen der bestehen- den Problematik, ein interdisziplinäres Deuten, ein zielgerichtetes War- nen und ein abgestimmtes Handeln im Krisenteam beinhalten.}

\subsubsection{Das Phänomen des Leaking}

Die meisten Amokläufer und School Shooter teilen ihre Absichten im Vorfeld mit, was als „Leaking“ bezeichnet wird. Dabei lassen sie ihre Tatfantasien oder -pläne entweder in Zeichnungen, verbal oder in schriftlichen Äußerungen oder durch das demonstrative Tragen von Tarnkleidung und durch ihr Interesse am Sammeln von Informationen über Gewalt, Waffen, School Shooting „durchsickern“.

Bei Georg R., dem Schulamokläufer von Ansbach, wussten seine Lehrer, dass er sich mit dem Thema „Amoklauf“ beschäftigte. Er wollte sogar eine Facharbeit über Amokläufe schreiben.

Um schwere, zielgerichtete Formen von Schulgewalt zu verhindern, sind diese Ankündigungen und Hinweise von größter Bedeutung. Hier liegt der „Schlüssel“ zu einer effektiven Prävention und Erarbeitung einer Präventionsstrategie. Wichtig ist dabei, ernstzunehmende Androhungen von harmlosen Späßen zu unterscheiden, damit eine Tat verhindert werden kann.

Mittlerweile gibt es wissenschaftlich fundierte Checklisten zur Einschätzung der Gefährlichkeit des Leakings Scheithauer et al. (2009) begannen ein von der DFG gefördertes Forschungsprojekt an Berliner Schulen, um Leaking frühzeitig zu erkennen und Krisenteams die Chance zu geben, schnelle Interventionen zu vornehmen. Neuerdings sind Schulen anderer Bundesländer wie Baden-Württemberg einbezogen.

\section{Woran Leaking erkannt werden kann}

- Briefe, gewalttätige Zeichnungen, Liedtexte, Droh- und Belästigungsanrufe, Mitteilungen in Chatrooms, durch Weblogs, per E-Mail oder SMS sowie durch Verschickung von Videosequenzen im Internet sind direkte Formen des Leakings. Indirekt können sich potenzielle Täter durch Tragen von Tarnkleidung, Waffen „outen“.

- Formen des Leakings sind ebenfalls häufige Verbalaggressionen, konfrontative oder einschüchternde Äußerungen, Schuldzuweisungen an andere.

- Die Täter kommunizieren ihre Absichten meist in Richtung ihrer „Peer-Gruppe“, die dadurch zu wichtigen Informationsträgern wird.

- Intensive Darstellung ihrer Beschäftigung mit „Helden-Mythen“, verschiedenen Formen von Gewalt, Formen des Selbstmords und eigenen Tötungs- 
wünschen. Äußerungen von Ausweglosigkeit, Wahrnehmung eines Tunnelblicks.

- Der Medienkonsum ist weitgehend gewaltorientiert und auf gewalttätige Literatur gerichtet.

- Äußerungen von Hoffnungslosigkeit, von tiefen Ressentiments und Wünsche nach Rache gegenüber Lehrer und Mitschüler.

- Berichte über Erfahrungen mit Schusswaffen und Messern, Faszination für Waffen mit ersten Probehandlungen.

- Drohungen, Waffen in die Schule mitzubringen, wobei zwischen flüchtigen oder substanziellen Drohungen und Gewaltplänen unterschieden werden muss.

- Suche nach Unterstützung von Mittätern.

- Auftauchen von Hasslisten mit einem „Opferpool“

Wer Leaking-Zeichen erkennt und angemessen reagiert, hat die Chance, einen Amoklauf und das School Shooting zu verhindern.

\subsubsection{Das „Dynamische Risiko Analyse System“ (DyRiAS) ${ }^{\circledR}$ nach Hoffmann}

Hoffman et al. (2009) vom Institut für Psychologie und Bedrohungsmanagement (2009) entwickelten - basierend auf Forschungsarbeiten der Arbeitsstelle für forensische Psychologie der TU Darmstadt - das „Dynamische Risiko Analyse System“ (DyRiAS) ${ }^{\circledR}$ - eine Software, um schwere Gewalttaten vorhersagen zu können. Dies geschieht durch die Ermittlung und Auswertung von 32 erkennbaren Warnsignalen. Das Programm konnte alle bis 2008 bekannten deutschen und US-amerikanischen Amokläufe an Schulen „voraussehen“. Bei der Nutzung des Programms beantworten Schulpsychologen, Lehrer und Polizisten Fragen zu anonymisierten Tätern. Diese Informationen werden eingegeben und das Programm erstellt einen Risikoreport. Indikatoren, die jedoch sicher auf eine Gewalttat schließen lassen, gibt es nicht! Nicht jede Kritzelei auf der Schultoilette sollte Anlass zur Sorge geben. Wichtiger als einzelne Indikatoren sind einzelne „Puzzlesteine“, die zusammen erst ein Bild ergeben.

In Zürich benutzt die Fachstelle für Gewaltprävention das „Risiko Analyse System“ seit 2009. Bisher konnte in allen bearbeiteten Fällen nach eingehender Analyse Entwarnung gegeben werden, was eine große Entlastung für das Krisenteam aus Lehrern, Schulpsychologen, Polizisten und Mitarbeitern der Fachstelle für Gewaltprävention bedeutete (Langer und Diehl 2009).

\section{Kriterien der Gefahreneinschätzung durch das „Risiko Analyse System“} nach Hoffmann et al. (2009)

Sieht der Jugendliche Gewalt als einzige Lösungsstrategie an?

- Stimmen die Äußerungen mit seinen Handlungen überein? 
- Welche Umstände könnten die Wahrscheinlichkeit weiterer Ausbrüche von Gewalt beeinflussen?

- Was sind die Motive und Ziele?

- Gibt es anhaltende Verlust- und Kränkungserfahrungen und wie werden diese aktuell verarbeitet?

- Existiert ein ungewöhnliches Interesse an Waffen und an Gewalttaten?

- Wie sehen die tatvorbereitenden Handlungen aus?

- Hat der Jugendliche eine Bindung an einen für ihn verantwortlichen Erwachsenen?

- Gibt es eine Vorgeschichte von Depressionen, Gedanken und Impulsen suizidalen Charakters?

- Zeigt der Jugendliche kognitive Verzerrungen und Denkverengungen?

- Berichtet er von desillusionierenden Erfahrungen?

- Hat er noch Ressourcen?

- Ist er weitgehend isoliert?

- Befasst er sich nur noch mit Internetseiten, die sich mit Amoktaten beschäftigen?

Wie groß ist seine Faszination für Waffen?

- Hat er sich konkret bewaffnet?

- Hat er schon Mitschüler mit Waffen bedroht?

- Wie groß ist die Faszination für „Ballerspiele“ und versucht er diese in der Realität auszuleben?

- Wie groß ist sein „Rachebedürfnis“ an der Gesellschaft?

- Ist er ein Einzelgänger oder gibt es mehrere Täter?

- Betrachtet er sich als Ausgestoßener seiner Klassengemeinschaft?

- Zeigt er Anzeichen von Persönlichkeitsspaltung, Größenwahn und Minderwertigkeitskomplexe?

- Besitzt der Täter noch ein funktionierendes soziales Netz?

- Wie zeigt er seine Verachtung und Hass auf die Schwachen und sein Leiden unter den Starken der Schule?

- Hat er schon einmal den Wunsch geäußert, „ganz groß raus zu kommen“?

- Hat er zuletzt große Niederlagen erlebt und empfindet sich als „Looser“?

- Zeigt er einen von Verzweiflung geprägten Entwicklungsweg?

- Identifiziert er sich mit früheren Tätern?

- Hat er schon Todeslisten erstellt?

- Hat er schon seine Taten angekündigt?

- Ist der "point of no return“ schon erreicht?

Da die Taten oft im Vorfeld direkt oder indirekt angekündigt werden, ermöglichen diese Kriterien entscheidende Anhaltspunkte für die Identifikation potenziell gefährlicher Schüler.

Es gibt unterschiedliche Warnsignale, aber keinen Fall ohne Warnsignale! 
Die Martin-Niemöller-Schule im hessischen Riedstadt-Goddelau nutzt das Instrumentarium „DyRiAS“ nunmehr seit mehr als zwei Jahren. Dies verhindert nach Meinung des dortigen Krisenteams vor allem Überreaktionen und Hysterie, da die meisten Verdachtsfälle sich als harmlos entpuppen. Schießübungen alleine besagen nichts. Es gehe nach Meinung von Hoffmann (zit. nach Donner 2011) immer darum, ob sich das Verhalten des „potenziellen“ Täters in ein adäquates „Muster“ einordnen lässt.

\subsubsection{Die Gewalt-Fantasien des Täters}

Bei der Entwicklung eines Tatplans spielt die Fantasie des potenziellen Täters eine wichtige Rolle (s. Auszüge aus dem Fragebogen „Gewaltfantasien“ in Kapitel 8.2). Die Täter ziehen sich häufig in eine Fantasiewelt zurück, die ständig um Gewalt und um Vorstellungen von der eigenen „Großartigkeit“ kreist, um den negativ besetzten Gefühlen nach einer öffentlichen Demütigung zu entfliehen. Sie bedienen sich der Machtfantasien, um ihre Kränkungen zu kompensieren. Ihr Denken konzentriert sich immer mehr auf die Planung von Aktionen und Reaktionen (Wahl und Hees 2009).

Die konsumierte Bildschirmgewalt soll sich nach Meloy et al. (2001) umso stärker auswirken, je zeitnäher die Täter sic vor ihrer Tat aufnehmen. Sie tun das, um sich absichtlich zu stimulieren und um regelrecht in die Aggression „einzutauchen“ (aggression immersion). Weitere Warnsignale für bevorstehende Gewaltaktionen können sein:

- Die Täter fühlen sich bedroht und verfolgt.

- Sie entwickeln zunehmende paranoide Ideen bis hin zu generellen Wahnvorstellungen mit „Kommando-Stimmen“, Grandiositätsfantasien und Denkstörungen.

- Sie zeigen eine extreme Impulsivität, Zeichen von Depression und Stimmungsschwankungen.

- Sie haben Probleme im Anerkennen von Autoritätspersonen.

- Sie verfolgen andere Personen oder lauern ihnen auf.

- Sie richten ihren Spott oder Gewalt gegen andere oder selbst zu Opfern von Spott.

- Es kommt zu Sachbeschädigungen.

- Ihr äußeres Erscheinungsbild verändert sich.

Für die Erstbewertung der Frage: „Welche Art von Drohung liegt vor?“, ist auch die Typologie von Cornell (1999) geeignet:

Typ I: Erkennen von flüchtigen Drohungen

- Die Drohung enthält keine andauernde Intention, jemand schaden zu wollen.

- Sie ist eher Ausdruck eines momentanen Gefühls und aus der Situation heraus verstehbar. 
- Der potenzielle Täter ist noch zur Distanzierung von einer angedrohten Tat fähig.

- Er kann sich entschuldigen.

Typ II: Erkennen substantieller Drohungen und zielgerichteter Gewalt

- Die Drohung enthält spezifische und plausible Details.

- Es kommt zu wiederholten Äußerungen.

- Der potenzielle Täter zeigt konkrete Planungshandlungen.

- Er versucht, Komplizen oder Zuschauer zu gewinnen.

- Er ist im Besitz von Schusswaffen oder Todeslisten.

- Er nimmt seine Drohungen nicht zurück.

- Er hat die deutliche Absicht, jemandem zu schaden.

\section{Fallvignette nach 0'Sullivan (2008)}

Der jugendliche Amokläufer, der in Finnland im November 2007 in seiner Schule ein Blutbad anrichtete, bezeichnete sich auf „YouTube“ als „zynischer Existenzialist“. Wenige Monate nach seinem Tod tauchten auf „YouTube“ die Botschaften von Trittbrettfahrern auf im Namen des „Sturmgeists“ (Nickname) und seiner angeblich „zynisch-existentialistischen Generation“. Die Bewertung der Selbstmordattentäter fand damit möglicherweise eine genuin westliche Variante, als wenn nur Gewalt, das „Blut“ der „Blutrache“, die „verletzte Ehre“ wieder reinwaschen könnte.

Hoffmann et al. (2009) erwähnen das JACA-Modell mit seinen vier Dimensionen, das ebenfalls zur Beantwortung der Frage: „Welche Art von Drohung liegt vor?“, geeignet ist. Dieses Modell kann helfen, die jeweilige Sachlage mit den „Augen des Täters“ zu betrachten:

1. Justification oder die Rechtfertigung von Gewalt. In welcher Weise rechtfertigen potenzielle Täter ihr Verhalten oder ihre spezielle Kommunikation mit anderen Personen?

2. Alternativless oder der Wegfall von Alternativen. Zeigen sie noch Hoffnung auf eine Verbesserung ihrer Situation und haben sie noch Handlungsalternativen? Zeigen sie schon einen „Tunnelblick“ durch eine erhebliche Fixierung auf Gewalt?

3. Consequences oder die Folgen. Ist der potenzielle Täter bereit, die Konsequenzen seiner Gewalttat zu tragen? Äußert er Selbstmordideen, weil er nichts mehr zu verlieren hat? Spricht er schon in der Vergangenheitsform, im Sinne von „die Welt wird dann sehen und erkennen, dass ich eigentlich ein Held bin“, als habe er schon von allem Abschied genommen? Zeigt er schon ein „Glimmen“ missionarischen Eiferertums?

4. Ability oder die Befähigung. Hantiert der potenzielle Täter schon mit Waffen und zeigt er konkrete Planungshandlungen? 


\section{Wenn ein potenzieller Täter schon mit Waffen hantiert, ist Handlungs- und Interventionsbedarf gegeben. Wegnahme der Waffen bedeutet: „Keine Befähigung mehr!“}

Die Einschätzung eines drohenden School Shootings und die daraus resultierende Intervention sind miteinander verknüpft. Eine Fallbewertung und das entsprechende Fallmanagement dürfen nicht statisch, sondern müssen im Sinne eines Prozessgeschehens dynamisch betrachtet werden. Jede Einschätzung der Gefahr muss mit Fakten belegt werden, wie es sich z.B. in der Änderung des Kleidungsstils (Trenchcoat), in selbst gefertigten Grafiken eines Grabsteins oder in einem Bild mit Waffen ausdrückt.

\subsubsection{Tatausgang}

Die Frage, wann der „Point of no return“ erreicht ist, ist ein Versuch, das „Unkontrollierbare unter Kontrolle“ zu bringen. Meist gibt es einen letzten akuten TatAuslöser, z.B. eine Beziehungskrise, Trennung, Zurückweisung, Zuspitzung der Schulprobleme oder andere Stressoren. Die letzten Bindungen zu Familie und sozialem Umfeld sind zerrissen. Man muss fragen: „Hätte eine Ansprache vor der Tat geholfen und durch wen?" Eine Frage, die nach solch schrecklichen Ereignissen immer wieder gestellt wird.

Harris und Klebold scheinen ihre selbst erschaffene Wirklichkeit in Erstaunen versetzt zu haben. Nachdem sie ihr letztes Opfer getötet hatten, streiften sie noch vierzig Minuten lang ziellos durch die Gänge der Schule, bevor sie sich selbst erschossen. Von den sieben deutschen School Shooter starben vier (Hoffmann et al. 2009).

Die Frage ist, ab welchem Moment man zu einem potenziellen Täter keinen Zugang mehr findet, da die Attraktivität und Faszination von Gewalt und Gewaltexzessen, sich selbst zu überschreiten, mit dem „Gefühl einer tiefgehenden, rauschartigen Erfahrung durch die unlösbare Verbindung von Gewalt und Tod überwiegt" (Bataille, zit. nach Wiechens 1995).

\subsection{Wie wird Gewalt ausgeübt?}

Es stellt sich die Frage nach der Art und Weise des Vorgehens und nach den eingesetzten Mitteln. Welche Waffen wurden verwendet? Waren Dritte beteiligt, die weitere Gewalt ermöglichen können?

Für die Jugendlichen besteht trotz des bestehenden Waffengesetzes jederzeit die Möglichkeit, an Waffen zu kommen. Das Internet bietet hierzu vielfache 
Möglichkeiten. Die bisherigen Fallanalysen zeigen die Benutzung unterschiedlichster Waffen. Neben Gewehren wurden Molotowcocktails, Messer, Äxte oder Samurai-Schwerter benutzt. 44\% der Täter benutzten die Waffen von Eltern und Verwandten. Nahezu alle waren von Waffen fasziniert und zeigten im Vorfeld Probehandlungen. Einige Jugendliche suchten nach Unterstützung durch Mittäter.

Georg R. benutzte bei seinem Schulamoklauf im September 2009 Brandsätze und ein Beil. Er verletzte 15 Personen, bis ihn schließlich Polizisten mit drei Schüssen auf der Jungentoilette stoppen konnten. Georg R. hatte auch über die Verwendung von Schusswaffen nachgedacht, aber keine Chance gesehen, sie zu bekommen.

Fallbeispiel Peter. Er dachte an die Möglichkeit, sich Waffen zu besorgen, u.a. auch über das Internet. Er schreckte jedoch vor diesem Schritt zurück. In seinem unmittelbaren Umfeld hatte er keinen Zugang zu Waffen.

\subsection{Wem gilt die Gewalt?}

Wer sind die Opfer einer Gewalthandlung? Robertz (2004, 2007) stellte fest, dass jeweils ungefähr in je einem Drittel der Fälle ausschließlich das Lehrpersonal oder ausschließlich Mitschüler oder sowohl Schulpersonal als auch Schüler verletzt wurden. Vossekuil et al. (2002) geben einen Lehreranteil von 54\% an.

Fallbeispiel Peter. In seinem „Opferpool“ befanden sich einige Lehrer, von denen er sich gedemütigt fühlte, sowie einige Klassenkameraden, von denen er sich gemobbt fühlte, sowie ein für ihn "unerreichbares" Mädchen.

Georg R., der Schulamokläufer von Ansbach, sagte in seinem Prozess, dass er gezielt mit seiner Bluttat im dritten Stock des Gymnasiums „Carolinum“ begonnen habe. Seine Opfer habe er zufällig ausgewählt. Sie seien für inn keine Lebewesen gewesen. Auch sich selbst habe er nicht als einen Menschen gesehen, der es Wert gewesen sei zu leben. Das Gericht ordnete neun Jahre Jugendhaft und Einweisung in die Psychiatrie an. 


\subsection{Warum wird Gewalt ausgeübt?}

Die Frage nach den Ursachen und Gründen einer Tat wird von Mikos (2005) folgendermaßen beantwortet: Gewalt ist als eine Form sozialer Interaktion stets in soziale, ökonomische und kulturelle Strukturen eingebettet.

\section{Es gibt kein einfaches Ursache-Wirkungs-Modell!}

Wahl (2009) entwickelte das umfassende Modell zu den „bio-psycho-sozialen Mechanismen der Aggression" (s. Abb. 3).

Zusammengefasst enthält das Schema folgende Informationen: Sitz der mentalen und kognitiven Persönlichkeitsstrukturen ist das Gehirn mit seinen Instanzen des limbischen Systems und des präfrontalen Cortex. Die strukturellen neurologischen Grundlagen werden primär genetisch bestimmt und entwickeln sich vor allem in der Embryonalzeit. Später füllen kulturelle und gesellschaftliche Umgebungseinflüsse die neuronalen Strukturen mit mentalen Inhalten, führen aber auch zeitlebens zu Umstrukturierung und Anpassung des neuronalen „Outfits“ an neue Bedingungen. Vor allem im Verlauf der kindlichen Entwicklung bis zur Adoleszenz prägen Kontakte mit der Umwelt die Persönlichkeitsmerkmale. Motivation sowie Muster für impulsive und geplante Reaktionen wie auch des aggressiven Verhaltens werden damit weitgehend vorgeprägt. Kindliche Traumata sowie Defizite im kognitiven und emotionalen Bereich lassen Persönlichkeiten entstehen, die Schwierigkeiten haben, auf Bedrohung, Provokation und Frustration angemessen zu reagieren. Dies sind offenbar auch Voraussetzungen für die Entstehung zielgerichteter Gewalt.

\subsubsection{Gewalt aus entwicklungspsychologischer Sicht}

Physische Aggression tritt in der Kindheit zwischen dem Ende des ersten Jahres und des zweiten Lebensjahres als normales Entwicklungsgeschehen auf. Sie erreicht ihren Gipfel, wenn das Kind etwa $3^{1 / 2}$ Jahre alt ist, und nimmt ab, wenn das Kind mit der Beherrschung der Sprache und nach Entwicklung von Mitgefühl zu Alternativen fähig ist, um sich in seiner Umgebung durchsetzen zu können. Ungünstige familiäre Bedingungen und ungenügende Erziehungshaltungen der Eltern können aber ein erfolgreiches Herauswachsen der Kinder aus aggressivem Verhalten beeinträchtigen und maladaptive Formen von Aggression und sozialem Verhalten verstärken (Hoeve et al. 2009).

Für eine gesunde psychische Entwicklung muss ein Säugling die Erfahrung einer gesunden Bindung zwischen ihm und seinen Bezugspersonen machen. „Böse“ ist für das Kind in der ersten Lebensphase das, was es als frustrierend, 


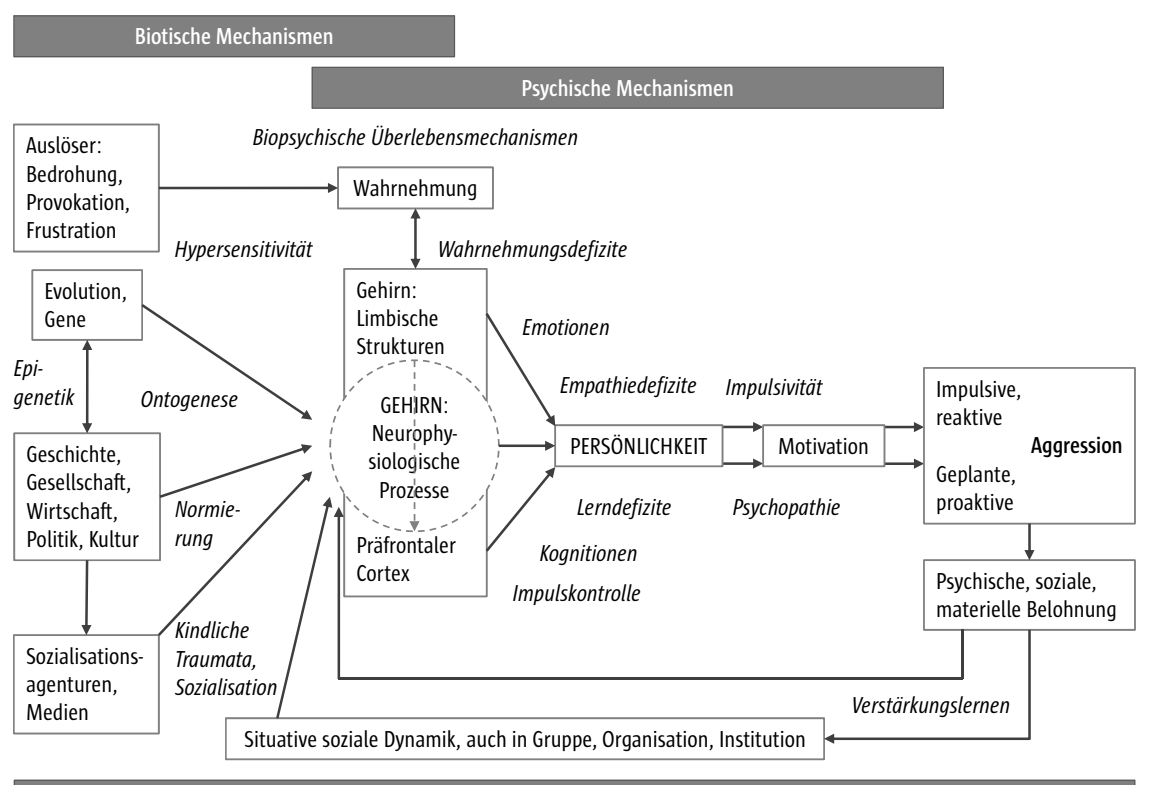

Soziale Mechanismen

Abb. 3 Modell zu bio-psycho-sozialen Mechanismen nach Wahl (2009)

bedrohlich und Angst erzeugend erlebt. Später kann es „Gut und Böse“ sprachlich benennen. Die ersten Schritte zur Gewissensbildung erfolgen im Sinne einer Konditionierung. Das Kind macht sich die Werturteile der Eltern von „Gut und Böse“, „Erlaubt und Unerlaubt“ zu eigen. Wichtig ist eine Erziehung der Kinder zu einer „gutartigen“ Aggression, im Sinne einer guten Streitkultur, die es ihnen ermöglicht, Meinungsverschiedenheiten auszuhalten, sie im Sinne eines „Fair-Play“ auszutragen, ohne dabei destruktiv zu werden (Klosinski 2008). Dabei müssen die Erziehenden verstehen, wie sich das „Böse“ in die Welt des Kindes „einnistet“ und welche Funktionen die kindliche Vorstellung über das „Böse“ und das „Böse-Sein“ einnimmt. Da die Außenwelt unsere Innenwelt und die Innenwelt unsere Außenwelt spiegelt und mitgestaltet, sind wir nach Klosinski (2008) angehalten, auch die „Dimension des Schrecklichen“ anzuerkennen. Psychische Faktoren, die „Böses“ hervorrufen, sind eine erhöhte Kränkbarkeit, im Sinne einer „narzisstischen Verwundbarkeit“, eine schlechte Frustrationstoleranz oder eine Abhängigkeit, die häufig zu Wutreaktionen führen. Nicht selten sind dabei die aggressiven Verhaltensweisen Ausdruck einer Angst, die abgewehrt werden muss. Angst und Aggression sind „zwei Seiten einer Medaille“.

\section{Angst dient oft als Aggressionsabwehr und Aggression als Angst- abwehr.}


Weitere Wurzeln des „Bösen“, die zu einer reaktiven aggressiven Einstellung führen können, sind Gefühle des Verlassenseins, der Wut über mangelhafte Zuwendung und fehlende Aufmerksamkeit. Dabei können die verschiedenen Ängste, wie sie durch Verlust von Körperkontakt, Trennung, Überforderung, Versagensängste sowie Reifungs- und Bindungsprobleme entstehen, zu AutoAggression oder zu Fremd-Aggression führen.

Die von der entwicklungspsychologischen „Theory-of-Mind“-Forschung angeregte und auf Fonagy et al. (2004) zurückgehende Wortprägung „Mentalisierung“ kennzeichnet die „geistige Leistung des Kindes, Ausdruck, Tun und Handeln der Menschen in intentionaler Perspektive“ zu verstehen. Nach Meinung von Fonagy et al. (2004) entfaltet und differenziert das Kind bis zum vierten und fünften Lebensjahr sein Bild vom seelischen Leben anderer Menschen zu einer „Alltagspsychologie des Fremdseelischen “, die der Vorstellungswelt Erwachsener bereits recht nahe kommt. Doch bedarf es dazu einer „responsiven und steuernden Umgebung“.

Menschen erreichen ihre Selbstständigkeit und Selbstwirksamkeit bei der Regulierung ihrer Bedürfnisse durch aktives und gezieltes Handeln sowie durch Suche nach Hilfe bei anderen. Auch hier entsteht bedarfs- und plangerechtes Handeln aus dem Zusammenspiel von kindlicher Expressivität und elterlicher Pflege in den Formen des Forderns und Gebens von Resonanz, von Unterstützung und Verständnis. Die Beziehungspersonen des Kindes sollten in dieser Entwicklungsphase sein Ausdrucksverhalten in markanter und akzentuierter Weise vorführen. Dies wird nach Boothe (2011) als „Affektspiegelung“bezeichnet. So zeigen die Eltern dem Kind, dass sie seinen emotionalen Zustand verstehen. Sie behandeln das Kind als Person, dessen emotionale Regungen für sie relevant und bedeutsam sind. Diese „Ordnung der Erfahrung“ ist „narrativ“. Das Kind lernt, seine eigene Stärke zu erproben und erwirbt ein „Repertoire der Attacke, der Bemächtigung und der Gegenwehr“. Die Verfügung über aggressive Ressourcen schafft auch eine Selbsteinschätzung der eigenen Wirksamkeit und Einflussmacht.

Es hat den Anschein, dass vielen Eltern in der heutigen Zeit eine authentische Spiegelung in adäquater und kindgerechter Form nicht mehr gelingt. Auch ein zu starkes Umsorgen und Verwöhnen bis hin zur „Wohlstandsverwahrlosung“ kann sich negativ auf das Selbstwertgefühl des Kindes auswirken und zu Störungen der Selbstwert-Regulation führen. Dadurch wird die Fähigkeit zur Selbstreflexion nicht ausgebildet und dieser Mangel geht mit Störungen in der „Gedächtnis- und Repräsentanzenbildung“ (Fonagy 2008) einher, wobei das Gedächtnis sowohl deklarative und prozedurale Qualitäten wie auch explizite und implizite Inhalte umfasst.

Während sicher gebundene Kinder ihr ,implizites“ Wissen als ,potenziell evozierbares Reservoir" für die Beziehungsregulierung verwenden, gibt es in der Entwicklung bei Kindern und Jugendlichen mit schweren Traumatisierungen breite Ausfälle in der Gedächtnis- und Repräsentanzenbildung infolge von 
Mentalisierungsstörungen und - traumatisch bedingt - nicht abrufbaren Gedächtnisinhalten (Amnesien). Deshalb stellen sie traumatische Erfahrungen, wie Erfahrungen von Gewalt, überwiegend handelnd und „reinszeniernd“ dar.

Eine frühe problematische Beziehung zwischen Kind und Bezugspersonen kann nach und nach zu Entwicklungsstörungen führen, vor allem zu Problemen mit der Impulskontrolle, zu mangelnder Empathie und zu verringerter Fähigkeit, Konflikte zu lösen. So belegen zahlreiche Studien nach Fonagy et al. (2004) den engen Zusammenhang von Misshandlung in der Kindheit und späterer Gewaltbereitschaft.

In der Entwicklung von Gewaltverhalten spielt es offensichtlich eine große Rolle, ob Fähigkeiten der Selbstregulation in der frühen Kindheit ausgebildet werden, um für die normalen physiologischen Regulationsvorgänge während der Adoleszenz gerüstet zu sein. Kognitive und exekutive Kompetenzen, die in den ersten zwei Jahren entwickelt werden, sind wichtige Prädiktoren für spätere selbstregulatorische Fähigkeiten. Eine unsichere Bindung zwischen Bezugsperson und Kind führt dazu, die Haltung der Bezugsperson zu internalisieren. Das Kind sieht Hass und Ekel in der Mimik der Eltern und denkt: „Ich bin hassenswert, wie das, was ich sehe“. Es kommt zu einem „Stopp der Mentalisierung“. Flucht scheint dem Heranwachsenden dann nur noch durch Selbstzerstörung möglich zu sein.

Bei der "desorganisierten“ Bindung und "Introjektion eines fremden Selbst“ (Peichl 2008) aufgrund einer ständigen Bedrohung durch physische, vor allem sexuelle Gewalt neigen Kinder dazu, sich im weiteren Verlauf der Entwicklung Selbstverletzungen zuzufügen sowie Dissoziationen und zwanghafte Handlungen zu entwickeln. Die „innere Welt“ wird dann als eine äußere „Missbrauchswelt" erlebt und umgekehrt. Nach Fonagy (2008) wird diese Gleichsetzung als „Äquivalenzmodus“ bezeichnet. Dabei vermischen sich beim Kind die beiden Welten, oder Teile der erlebten Welt werden im Sinne des „Als-ob-Modus“ nach durch Dissoziation ausgeblendet. Die Vorstellungen des Kindes sind innerlich und symbolisch, während die Realität außer Kraft gesetzt ist. Bei dem dadurch entstehenden Gefühl der Leere und des Abgetrenntseins von der Umwelt bewirkt der „Als-ob-Modus“ eine zwanghafte Suche nach einem Sinn, die als „Sichverrückt-machen" beschrieben wird.

Typisch für eine Traumatisierung ist ein „Hin- und Herpendeln“ zwischen diesen beiden Modi als eine Art der Bindungsstörung, die im kinder- und jugendpsychiatrischen Alltag als „Bindungsstörung mit Enthemmung“ (F 94.2. nach ICD-10) beschrieben wird (s. Box).

\section{Bindungsstörung mit Enthemmung (F 94.2. nach ICD-10)}

- Abnormes soziales Funktionsmuster während der ersten 5 Lebensjahre

- Persistenz der Milieufaktoren

- Diffuses, selektives Bindungsverhalten 
- Aufmerksamkeitssuche

- Wahlloses Kontaktverhalten

- Kaum modulierte Interaktionen mit Gleichaltrigen

- Emotionale und Verhaltensstörungen

- Allgm. Anklammerungsversuche im Kleinkindesalter

- Schwierigkeiten im Aufbau enger, vertrauensvoller Beziehungen zu Gleichaltrigen

- Mangelnde Kontinuität der Betreuungspersonen/mehrfache Wechsel/ Unterbringungen

- Gefühlsarme Psychopathie

- Heimsyndrom

\section{Fallvignette}

Georg R., der Schulamokläufer von Ansbach, äußerte in seinem Prozess vor dem Landgericht, dass für ihn seine geschiedenen Eltern keine Vertrauenspersonen gewesen seien. Sein Vater war selbst psychisch krank. In den Monaten vor seinem Gerichtsprozess habe er begonnen, sich selbst besser zu mögen, habe sich in den Kreis seiner Mitpatienten besser integrieren können, empfände Scham über seine Tat und sehe es als wichtigstes Ziel seiner Therapie an, Mitgefühl für andere empfinden zu können.

Fonagy (2008) sieht im Gewaltverhalten ein Signal für kindliche Fehlentwicklung, während er angemessene Aggression als normalen Bestandteil der Entwicklung betrachtet. Diese Unterscheidung ist nach Streeck-Fischer (2010) hilfreich, weil es, ihrer Meinung nach, in der Entwicklung des Kindes darum geht, aggressive Potenziale zu sozialisieren, was mit „Mentalisierungsprozessen“ einhergeht. Diese psychischen Phänomene haben nach Meinung von Böhm und Kaplan (2009) große Bedeutung dafür, ob jemand auf Rache verzichten und sich nach erlittener Demütigung oder nach Verlusterlebnissen mit dem Rachebedürfnis angemessen auseinandersetzen kann. Über Hass und Genugtuung nachdenken zu können, ist für das Kind ein Schritt, von Rache abzusehen.

Normale aggressive Ressourcen sind von denen zu unterscheiden, die mit einem destruktiven Potenzial einhergehen, denn destruktives Verhalten führt letztlich dazu, ein Opfer zu schwächen oder zu vernichten und dient nicht der „Optimierung der Selbstzentrierung“( Boothe 2011).

Hinsichtlich der Phänomene Amoklauf und School Shooting stellt sich die Frage, ob Täter oder potenzielle Täter in ihrer Entwicklung ausreichend Gelegenheiten hatten, effektive und angemessene Handlungsweisen zu entwickeln. Denn nur dann hätten sie die Möglichkeit gehabt, ihr Leben adaptiver 
zu gestalten, „Relikte“ aus der Vergangenheit zu überwinden und „unabgeschlossene“ Angelegenheiten - wie alte Kränkungen - aufzulösen. Wenn sie das aber nicht erlebt haben, erleben sie die Zukunft als Wiederholung ihrer als katastrophal erlebten Vergangenheit. So bleibt es nicht aus, dass ihre Handlungen oft durch verwirrte und verzerrte Realitätswahrnehmung gekennzeichnet sind.

Zur Entwicklung eines realistischen Selbstbilds gehört auch die Präsenz des Vaters. Meist findet man im Erstkontakt mit Eltern und dem vorgestellten Kind einen mehr oder weniger verdeckten Machtkampf zwischen den Eltern um die „richtige“ Erziehung. Hinter diesem Streit zeigt sich oft eine „symmetrisch" definierte Partnerschaft mit erheblichen Disqualifikationen der Handlungen des anderen Partners. In den Selbstbeschreibungen der Eltern findet man oft kognitive Aspekte des Verlusts der „,parentalen Wirksamkeitsüberzeugung“, der affektiven Wahrnehmungsverzerrungen oder der Angst, vom Kind nicht angenommen oder sogar gehasst zu werden. Die Eltern geraten dann immer mehr in eine „Parentale Hilflosigkeit“ (Pleyer 2003; vgl. Abb. 4), die durch folgende Tendenzen gekennzeichnet ist:

1. Selektive Wahrnehmung und Fehldeutung kindlicher Signale durch die Eltern. Die Bemühungen des Kindes, verstanden zu werden, sind zum Scheitern verurteilt. Dies frustriert das Kind und führt meist zu einer „Erhöhung des kommunikativen Aktivitätsniveaus“, was wiederum im Sinne von „Bösartigkeit“ als "Charakterdefizit“ oder als „Krankheit“ des Kindes von manchen Eltern gedeutet wird.

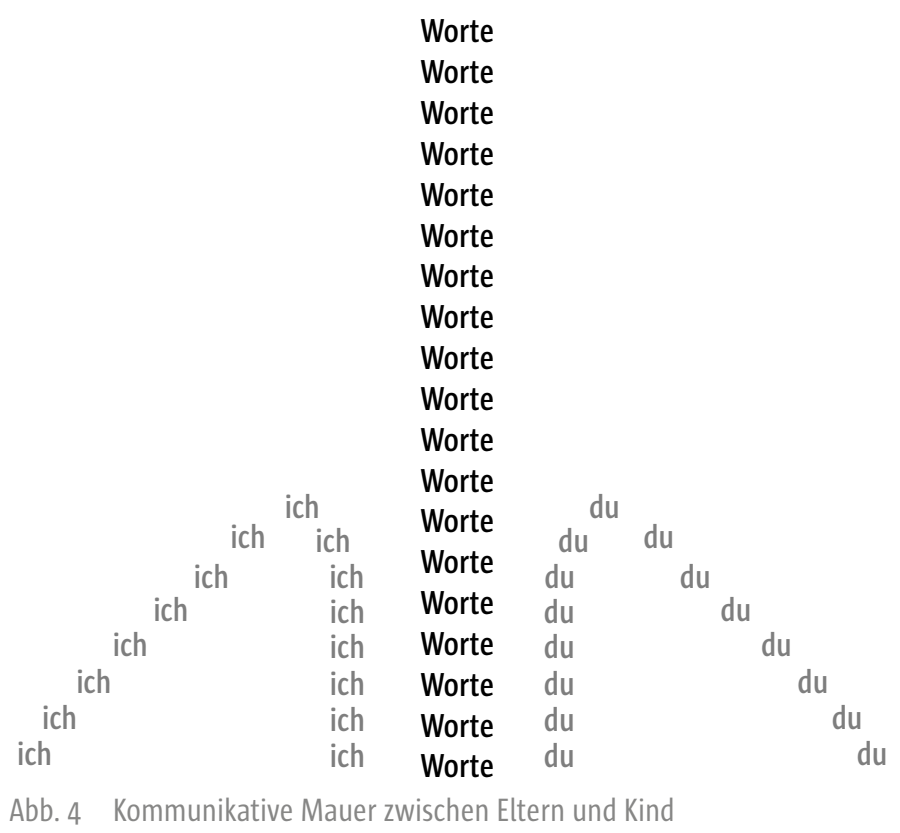


2. Konfliktvermeidung. Der Umgang mit dem Kind ist oft durch subtile Kritik, Abwertungen und Provokationen gekennzeichnet. Andererseits weichen die Eltern aus, Positionen zu beziehen, wo sie eigentlich gefordert sind, dies zu tun. Sie vermeiden es, Entscheidungen zu treffen. Gehäuft findet man undeutliche Bindungssignale, Erstarrungen in affektiven Reaktionen, Verlust des Sprechens und des Handelns. Positionierungsversuche der Kinder werden nicht oder unzureichend zur Kenntnis genommen.

3. Distanzierung von elterlicher Verantwortung. Man findet oft eine Tendenz zu einer aktiven oder passiven Abgabe von Betreuungs- oder Entscheidungsverantwortung an Außenstehende. Es besteht dann meist die Überzeugung, dass nur noch andere Personen oder Institutionen an ihr Kind „herankommen“.

\subsubsection{Frühe Traumatisierung und Gewaltbereitschaft}

Viele Jugendliche, die zu Gewalt neigen, erfuhren in ihrer Entwicklung multiple Traumatisierungen von ihren Bezugspersonen durch Vernachlässigungen oder Misshandlungen. Sie sind danach oft nicht mehr in der Lage, ihre Erfahrungen sprachlich mitzuteilen. Da sie sich nicht aus der Perspektive eines anderen betrachten können, haben sie auch Schwierigkeiten, ihr Verhalten angemessen zu reflektieren. Wenn sie jedoch über ihre traumatisierenden Erfahrungen sprechen können, fällt auf, dass sie diese auf unauthentische Weise als selbstkonstruiertes Narrativ darstellen, das den tatsächlichen Ereignissen nicht entspricht. Was sie wirklich erlebt haben, kann nur im interaktiven Austausch an ihren Handlungen wahrgenommen werden, denn traumatisierte Kinder neigen $\mathrm{zu}$ „Reinszenierungen“ und zu Interaktionen, die mit den früheren Erfahrungen zusammenhängen. Es gelingt ihnen jedoch keine angemessene Betrachtung dessen, was in der Vergangenheit geschah, weil sie keine differenzierte Vorstellung von Vergangenheit, Gegenwart und Zukunft besitzen.

Für traumatisierte Kinder existiert die Vergangenheit meist nur in der Gegenwart, da sie ihre negativen Erlebnisse immer wieder zwanghaft reinszenieren müssen.

\subsubsection{Zur Phänomenologie des Schmerzgedächtnisses}

Schmerzen gehen in das Gedächtnis des Leibes ein und entfalten nachhaltige Wirkung. Nichts prägt sich dem impliziten oder leiblichen Gedächtnis so ein wie der Schmerz. Wiederholte Schmerzreize regen „nozizeptive“ Neurone des Rückenmarks zu Wachstum und engerer Verschaltung an. Gleichzeitig ver- 
größern sich die entsprechenden neuronalen Netzwerke in der sensorischen Hirnrinde (Fuchs 2008). Schmerz und Bewegungs- wie auch Fluchtimpulse sind aneinander gekoppelt. Über die Amygdala bilden sich schließlich die Assoziationen von Schmerz und ihren auslösenden Situationen, die als bedrohlich wahrgenommen werden. Im Unterschied zu anderen Emotionen stumpft die Schmerzempfindung nicht ab (Fuchs 2008). Der Leib sensibilisiert sich und versucht sich zu schützen.

\section{Schutzmechanismen zur Schmerzlinderung}

- durch vorwegnehmende Anspannung

- durch „Einkrümmung" des Körpers

- durch Schonhaltung

- durch Vermeidung gefährlicher Situationen

Menschen mit Depersonalisationserlebnissen versuchen häufig ihre Selbstentfremdung und Empfindungslosigkeit durch Selbstverletzungen zu durchbrechen. Schmerz kann somit auch zu einem „Modus des Selbsterlebens“ werden (Fuchs 2008). Die Form der Schmerzerinnerung ist die Wiederholung durch Reinszenierung, durch automatische Reaktivierung der traumatisch eingeprägten „Engramme“. Schließlich kehren diese „Spuren des Traumas“ in Schmerzsymptomen, Somatisierungen bis hin zu Essstörungen oder Depressionen, die auf ein ,unaussprechliches Geheimnis“ hinweisen und gleichzeitig davon ablenken (Fuchs 2008).

\subsubsection{Täter-Introjekte und Aggression}

Peichl (2010a) geht bei männlichen Jugendlichen, die eine frühe Traumatisierung durch massive Gewalterfahrung und Vernachlässigung erlitten haben, von einem „Täterintrojekt“ aus. Darunter versteht man eine Inkorporation von traumatisierenden Erfahrungen als „Einpflanzung ins Ich“. Dadurch ist die schädigende Bindungsperson im Inneren des Kindes vorhanden. Die „Täterintrojekte“ betätigen sich dann als ,innere Kritiker" oder ,innere Verfolger“.

Es gibt verschiedene Formen der Introjektion:

\section{Adaptive Introjektion mit Hilfe des „inneren Kritikers“ im Gewissen}

Bei der Entstehung eines „einfachen Introjekts“ waren die Eltern für das Kind emotional unerreichbar. Sie zeigten sich am Kind desinteressiert, verhielten sich depressiv klagend und waren nur mit sich selbst beschäftigt. Eine angemessene „Spiegelung“ im Dialog mit den Eltern gelang nicht. Das Kind konnte keine „mentale Abbildung“ seiner Bezugspersonen seiner inneren Welt internalisieren, um ein eigenes Selbst auszubilden. 
Fallvignette aus dem Buch von Shriver (2009)

„Kurz vor seinem sechzehnten Geburtstag richtet Kevin in der Schule ein Blutbad an, was auch das Leben seiner Mutter schlagartig verändert. Von allen verurteilt, findet sie den Mut, sich in selbstkritischer Weise mit sich auseinanderzusetzen. Als ihr Sohn geboren wurde, fühlte sie nichts. Als der Säugling sich auf ihrer Brust wand, vor der er sich abgestoßen fühlte, strafte sie ihn im Gegenzug mit Zurückweisung - Ausgangspunkt einer schwierigen Bindung. Ab diesem Moment begann ein stiller, letztlich aber auch unbarmherziger gegenseitiger Kampf.“

Die „einfachen“ Introspekte sind oft mit unterschiedlichen Botschaften „gekoppelt":

\section{Unterschiedliche Botschaften von Müttern aufgrund eigener dys- funktionaler Glaubenssätze}

- Depressive Mutter: „Ich bin ohnmächtig, die Welt ist schlecht“ oder "Ich bin selbst ein Opfer und hilflos".

- Sich aufopfernde Mutter: „Ich muss mich für das Kind aufopfern“.

- Unerreichbare Mutter: „Ich brauche niemanden und lasse niemanden an mich heran“.

Im Kind schlägt sich diese Beziehungserfahrung als Introjekt in Gestalt einer „gefühllosen, kalten Mutter“ nieder. Es selbst empfindet sich als nicht angenommen, minderwertig und „klein“. Dies kann bei einer narzisstischen Entwicklung kompensatorisch zu einem „grandiosen“ Selbsterleben führen.

Maladaptive Introjektion mit einem unterdrückenden, feindseligen Introjekt

Je hasserfüllter und ablehnender eine wichtige Bezugsperson auf das Kind reagiert, umso stärker steigt der „traumatogene Stresspegel“im Kind. Weil die Eltern das Kind aktiv ablehnen und in aggressiver Weise zurückweisen, schaltet das „Notfallprogramm“ des Kindes auf Dissoziation.

\section{Destruktive Botschaften von Müttern}

- Feindlich eingestellte Mutter: „Meine Bedürfnisse sind immer wichtiger als Deine“. „Du bist wertlos, wärest Du nicht geboren“.

- Ausbeuterische Mutter: „Du musst für mich da sein“.

- Bindungsverstrickte Mutter: „Du bist wie ich, du kannst ohne mich nicht überleben“.

- Distanzierte Mutter: „Erwarte nichts von mir, du bist mir gleichgültig". 
Introjekte können im Verlauf der weiteren Entwicklung des Kindes und Jugendlichen ihre eigene aggressive Dynamik entwickeln.

\subsubsection{Theorie der strukturellen Dissoziation}

Aufgrund der oben beschriebenen Entwicklungen kann es im Kind zu einer „Aufspaltung des Selbsterlebens“ kommen, wie sie durch die Theorie der „Strukturellen Dissoziation“ von Nijenhuis (2009) beschrieben wird. Die „Aufspaltung des Selbsterlebens" unter traumatischen Bedingungen geschieht insbesondere an den „Sollbruchstellen“ im Rahmen der verschiedenen angeborenen Handlungsund Aktionssysteme, die zur Steuerung der Anpassungsfähigkeit in der Umwelt dienen.

Die wichtigste „Aufspaltung im Selbsterleben“ ist die zwischen „Alltagssystem“ und „Verteidigungssystem“.

\section{Aufspaltung des Selbsterlebens nach Nijenhuis (2009)}

Alltagssystem zur Sicherung des Überlebens im Alltag. Das Alltagssystem kann sich in mehrere Aktionssysteme (states) unterteilen. Dabei entwickelt sich ein „anscheinend normaler Teil der Persönlichkeit (ANP)“, der u.a. für Reproduktions- und Bindungsaufgaben als Sorge für den Nachwuchs sowie für die Kontrolle des Energiehaushaltes zuständig ist.

Verteidigungssystem als Schutz- und Verteidigungsfunktionen bei Bedrohungen. Das „Verteidigungssystem “ kann sich ebenfalls in Aktionssysteme unterteilen, die von Nijenhuis als „Emotionaler Teil der Persönlichkeit (EP)“ bezeichnet werden.

Beide biologisch angelegte Systeme sind überlebenswichtig und kooperieren im Alltag bei Mensch und Tier zweckmäßig miteinander. Sie dienen der strukturellen Aufteilung der Persönlichkeit, um die Funktionsfähigkeit und das Überleben im Alltag zu sichern. Als Folge psychischer und physischer Traumatisierungen in der frühen Kindheit können diese Systeme nicht ausreichend für komplexere Bewältigungsstrategien integriert werden. Es kommt im individuellen „Bewusstseinssystem“ zu dissoziativen und strukturell dauerhaft verankerten Empfindungs- und Handlungsmustern. Dies ist die Basis einer dissoziativen „Ego-State-Bildung“.

Peichl (2010b) unternimmt den Versuch, Ego-States näher zu beschreiben und benutzt psychodramatische Bühnenmetapher. Ego-States haben eigene Wahrnehmungen, Motivationen und Rollen innerhalb der Gesamtpersönlichkeit. Sie haben eine in sich geschlossene Geschichte und können untereinander Konflikte erzeugen. 
Die Aufgabe dieser „Ego-States“ besteht darin, sich mittels „Projektion“ und „Identifikation“ gegenüber der aggressiven Bezugsperson mit Hilfe von Kampfstrategien der Wut, durch Feindseligkeit und selbstdestruktivem Hass vor erneuter seelischer wie körperlicher Verletzung zu schützen. Sie haben eine Art „Wächterfunktion“. Es gibt deshalb „Ego-States“, die Formen von Flucht repräsentieren, und „Ego-States“, die ängstlich, wütend oder unterwürfig reagieren.

Wenn Kinder noch nicht in der Lage sind, aggressive Bezugspersonen zu „mentalisieren“ und von ihnen „symbolische Repräsentanzen“ zu schaffen, besteht die Möglichkeit, dass sie das „böse“ Objekt als „Verfolger-Anteile“ „in sich aufnehmen" und somit introjizieren. Viele Traumatisierte fühlen sich von solchen Introjekten „gefoltert“, als fände der Missbrauch oder die Misshandlung weiterhin statt. Diese „Ego-States“ sind - so paradox dies klingt - nicht das Problem, sondern der Versuch der „Lösung“ eines Problems. Sie versuchen, den Traumatisierten vor einer weiteren Bedrohung zu schützen. Sie ermöglichen es, „proaktiv“ mit den Gefühlen der Wut und des Hasses fertigzuwerden und Empfindungen von Verletztheit, Angst und Scham zu vermeiden. Dabei unterdrücken sie jede Bindung, jede möglichen Abhängigkeiten oder emotionalen Bedürfnisse und richten ihre Wut meist internalisierend nach innen. Bei Jungen geschieht dies aber überwiegend externalisierend. Das ursprüngliche traumatische Erleben wird „reinszeniert“. Aufgrund der eigenen Hilflosigkeit versucht das traumatisierte Kind, der belastenden Situation durch „Schuldübernahme“ zu entfliehen.

Das Ziel der Ego-State-Therapie ist die Erzeugung von Co-Bewusstheit und Integration der verschiedenen States. Sie sollen dem Individuum helfen, schwierige Lebenssituationen und Krisen besser zu meistern, weil sie auch viele Ressourcen und Stärken in sich tragen. Adaptive Ego-States sind in der Regel flexibler als die traumbezogenen Ego-States, die das traumatische Ereignis als Kognition, Gefühl, Körpererinnerung, Bild- und Handlungsimpuls in sich tragen.

Generell gilt nach Peichl (2010b), dass die führende Qualität des überwältigenden Affekts wie Angst, Hass, Scham, Ekel usw. bei der Ausbildung der EgoStates eine wichtige Rolle spielt. Er ist der „Organisator“ der Ego-States.

Michaela Huber, Expertin für dissoziative Störungen, nimmt bei Amoktätern eine strukturelle Dissoziation an (mündlicher Hinweis von E. Berner, 14.10.2009).

\subsubsection{Gewalt aus tiefenpsychologischer Sicht}

Gewalt hat aus tiefenpsychologischer Sicht immer eine Vorgeschichte und ist Folge einer Krise. Sie ist eher ein „Stadium“ als eine „Persönlichkeitseigenschaft“. Gewalt ist einerseits ,lösungsorientiert“ und zielgerichtet mit der Verfolgung individueller Ziele, andererseits bedeutet sie auch eine allmähliche „Verengung der 
Alternativen“. Letztendlich ist jede Form von Gewalt aus einer subjektiven Sicht ein Versuch, aufgrund des erlittenen Unrechts „Gerechtigkeit“ herzustellen.

Mitchell (1995) versuchte, verschiedene Positionen zu vereinheitlichen. Seiner Meinung nach ist Aggression genetisch veranlagt. Sie taucht allerdings in einem Beziehungskontext auf und wird durch Umstände generiert, die als bedrohlich erlebt werden. Er fasst Aggression als „eine biologisch begründete und extrem mächtige Antwort auf eine subjektiv wahrgenommene Gefahr" auf. Aggression dient der Selbsterhaltung und Selbststabilisierung und stützt die Integrität des Selbst. Aggression tritt als Folge von Furcht und Mangel an Empathie und in Zuständen auf, in denen das Selbst von „Desintegration“ bedroht ist. Das Ausmaß der wahrgenommenen Bedrohung ist abhängig von der Qualität der frühen Erfahrungen von Bemutterung und der durch sie vermittelten Umweltbedingungen.

Leuzinger-Bohleber et al. (2006) benennen drei Modelle, die Gewaltverhalten mit Hilfe psychoanalytischer Annahmen erklären können.

\section{Erklärung des Gewaltverhaltens aus psychoanalytischer Sicht nach Leuzinger-Bohleber et al. (2006)}

- Gewalt kann ein Versuch sein, bei drohender Überwältigung und „Verschlingung " durch das primäre Objekt zwischen sich und dem anderen Distanz zu schaffen.

- Gewalt kann der Befreiung von einem „inneren Fremdkörper“ dienen, der sich unintegriert im Selbst befindet und „unmentalisiert" verbleibt.

- Auf einer „inneren Bühne“ agieren dann „zwei Imagines“, das „hilflose Selbst“, das verlassen worden ist, und die "tödliche Figur", die das eigene „hilflose Selbst“ angreift. Destruktivität wird hier als eine Notfallreaktion auf ein primäres traumatisches Desaster verstanden.

\subsubsection{Gewalt aus systemischer Sicht}

Aus systemischer Sicht werden Gewalt und aggressive Impulshandlungen durch das „Zusammenspiel“ verschiedener Faktoren und Einflussfelder beschrieben.

\section{Verschiedene systemische Faktoren}

n Die persönliche Situation des Täters. Geringe Fähigkeit zum Konfliktmanagement (skills) oder Flucht in eine „virtuelle“ Welt.

- Die familiäre Situation. Oft findet man ein „kühles Familienklima“ oder Schwierigkeiten des Täters mit seinem Elternhaus.

- Die schulische Situation. Die Person erfährt Kränkungen durch die Leistungserwartungen der Schule.

च Die Ebene der „Peer-Gruppe“. „Mobbing“, Zurückweisungen von möglichen (Wunsch-)Partnern. 
In jedem dieser „Transaktionsfelder“ (Guntern 1983) finden sich konkrete Auslösefaktoren und „Trigger“. Nahezu jeder Jugendliche hat Probleme in der jeweiligen Phase seiner Entwicklung und durchläuft sie mehr oder weniger erfolgreich im Sinne einer „Persönlichkeitsreifung“.

In den letzten Jahren ist eine deutliche Zunahme von Mobbing-Erfahrungen, insbesondere von Cyber-Mobbing in der Schule zu beobachten, wodurch Kinder und Jugendliche entweder in depressive und suizidale Krisen oder in aggressive Situationen eines Impulskontrollverlusts geraten. Meist sind dies die Kinder und Jugendliche, die für Demütigungen und Angriffe auf ihr Selbstwertgefühl besonders sensibel sind und mit suizidalen Handlungen reagieren können. Bei ambulanten Erstkontakten und stationären Aufnahmen gehört es inzwischen zum Standard, auch ihre medialen Aktivitäten abzufragen. Heute hat fast jeder Jugendliche Kontakte zu „Social Networks“.

Während Klewin und Tillmann (2006) der Meinung sind, dass Gewalt an deutschen Schulen nicht zugenommen habe, vertreten Schäfer und Korn (2005) die Meinung, dass die Situation an den Schulen immer schlimmer geworden ist. Ihre Untersuchungen ergaben, dass es Mobbing inzwischen in nahezu jeder deutschen Schulklasse gibt. Nach ihren Recherchen sollen eine halbe Million deutsche Schüler regelmäßig durch Mobbing schikaniert werden. Etwa ein Kind von fünfundzwanzig Kindern leidet massiv als Opfer von Mobbing, wobei es einmal oder mehrmals in der Woche Mobbing-Attacken über sich ergehen lassen muss. Alle Schularten werden mit diesem Problem konfrontiert. Mobbing-Fälle gibt es an Hauptschulen auf dem Land ebenso wie an Gymnasien in der Stadt. Nach Meinung von Schäfer und Korn (2005) wird das Thema „Mobbing“ in den Lehrerzimmern „gewaltig unterschätzt“. Daher fordern sie ein gezieltes Lehrertraining und eine breite öffentliche Diskussion.

Der Vorsitzende des Deutschen Philologenverbands (DPhV), Meidinger (2008), hält die von Schäfer und Korn (2005) angegebene Zahl von 500.00o MobbingOpfern für realistisch. Seiner Meinung nach ist es erschreckend, wie häufig solche Fälle von Lehrern lange Zeit unentdeckt bleiben. Er weist daraufhin, dass Lehrer oft „,aus allen Wolken fallen“, wenn sie erfahren, dass Kinder seit langer Zeit drangsaliert wurden. Insofern sei eine „erhöhte Sensibilität“ vonseiten der Lehrerschaft notwendig.

Das „Aufbrechen“ von Mobbing-Strukturen ist jedoch nach Meidinger (2008) eine ungemein „diffizile“ Aufgabe. Er betont, es sei Tatsache, dass die bekannten Muster zur Konfliktbewältigung - wie offene Diskussion in der Klasse oder Gegenüberstellung der Betroffenen - meist nicht zum Erfolg führen, sondern teilweise auch „kontraproduktiv“ sind. Die Aufklärung von Mobbing-Attacken werde auch dadurch erschwert, dass die Eltern der Täter deren Verhalten häufig ,decken“.

Insofern ist es nicht verwunderlich, wenn sich der „Hass“ und die „Rache“ von School Shootern in erster Linie gegen Mitschüler richten, von denen sie „ge- 
mobbt“"wurden oder gegen Lehrer, von denen sie gedemütigt worden sind oder von denen sie sich nicht unterstützt und geschützt fühlten.

\subsubsection{Gewalt aus neurobiologischer Sicht}

Aus neurobiologischer Sicht ist die Adoleszenz eine Phase der „Remodellierung“, die teilweise auch mit vorübergehenden Veränderungen kognitiver Leistungen einhergeht. Zahlreiche neurobiologische und neuropsychologische Experimente beschäftigen sich mit der „Gehirnmodellierung“ und damit mit dem „Umbau der Verschaltungen“, die im Gehirn während der Pubertät stattfinden. Diese beginnt mit einem überschießenden Wachstum und führt später zu einer selektiven Vernichtung von Synapsen (Spitzer 2009).

„Innere Kohärenz“ und „mentale Separation“ von Selbst und Objekt (Fonagy et al. 2004) setzen eine physische Anwesenheit einer anderen Person voraus. Ist diese Anwesenheit nicht gewährleistet, so kann es trotz einer zunächst guten strukturellen Entwicklung zu einer „Desorganisation entwickelter Strukturen“ kommen. Für die Adoleszenz typisch ist der „Scheideweg“ zwischen Identität und Identitätsdiffusion (Foelsch et al. 2010). Die Jugendlichen probieren neue Identitätsvorstellungen und neue soziale Rollen aus.

Die Dimension der Intimität und Solidarität in Beziehungen stellt den nächsten „Scheideweg“ dar. Voraussetzung für eine Identitätsausbildung ist das erlebte Subjektgefühl, die Selbstempfindung. Unter negativen oder riskanten Entwicklungsbedingungen kann die Identitätsausbildung, auch noch in der Adoleszenz, durch angeborene Vulnerabilitäten oder schwere seelische Traumatisierungen beeinträchtigt werden.

Barkley (1997) entwickelte ein „,neuropsychologisches Konzept zur Verhaltensinhibition“ und zeigte, dass die Aufmerksamkeitsregulierung vor allem mit „exekutiven Fähigkeiten" zu tun hat, die der Selbstkontrolle und einem zielgerichteten Verhalten dienen. Auf der Basis seines Modells der Entwicklung exekutiver und selbstregulatorischer Funktionen stellt er die Fähigkeit zur Verhaltenssteuerung, zu verzögerten Antworten und zur überwachenden Kontrolle auf vier Säulen:

1. Die Selbstregulation von Affektmotivation und Affekterregung. Der Prozess der Selbstregulation von Affekten beginnt im Alter von fünf bis zehn Monaten. Das Kind lernt, Erregungslevels zu regulieren.

2. Das Arbeitsgedächtnis. Es umfasst Fähigkeiten (s. Box), Ereignisse im Gedächtnis festzuhalten, rückblickend und vorausschauend zu betrachten, und die Fähigkeit zur Antizipation.

\section{Die Fähigkeiten des Arbeitsgedächtnisses}

- Retrospektive Funktionen ermöglichen, auf bereits entwickelte Verhaltenstrukturen zurückgreifen und sie benennen zu können. 
- Prospektive Funktionen führen zur Vorbereitung von Handlungen, zur Antizipation von Ereignissen oder zu einem "Verhaltensset".

- Die Fähigkeit, Ereignisse in einer exakten zeitlichen Sequenz festzuhalten, ermöglicht die Entwicklung eines Gefühls für Zeit.

- Die Fähigkeit, Zeit zu bestimmen und zu fühlen, ist notwendig, um antizipatorische Fähigkeiten für motorische Antworten zu ermöglichen.

3. Zur Internalisierung von Sprache. Sprache hat eine wichtige Funktion im Hinblick auf die Entwicklung der Fähigkeit zur Selbstkontrolle. Der Schritt eines Kindes, mit sich selbst zu sprechen, ist ein Meilenstein in der Entwicklung von Selbstkontrolle. Das „Sprechen mit sich selbst“ impliziert Fähigkeiten der Beschreibung und Reflexion, Fähigkeiten zur Problemlösung und Selbstbefragung und unterstützt regelgeleitetes Verhalten nach eigenen Vorstellungen. Gleichzeitig werden damit motorische Reaktionen gesteuert.

4. Wiederherstellung (Rekonstitution). Sie beinhaltet die Fähigkeit, auf neue und herausfordernde Aufgaben mit Hilfe der Sprache oder im motorischen Verhalten multiple und komplexe Antworten zu entwickeln. Damit verbunden ist auch die Fähigkeit zur Analyse und Synthese des Verhaltens, zur verbalen Ausdrucksfähigkeit und Verhaltenskompetenz sowie kreativen Lösungen.

Eine gesunde Entwicklung in diesen vier Bereichen führt zu Fähigkeiten der Verhaltenskontrolle und der Steuerung aggressiver Impulse. Der Erwerb dieser Fähigkeiten ist eingebettet in sichere Bindungsbeziehungen. Schon ab dem jugendlichen Alter lassen sich „Subtypen aggressiver Persönlichkeiten“ unterscheiden, die sich auch in Unterschieden hinsichtlich neuronaler Korrelate von Emotionalität widerspiegeln. Die „Neuorganisation“ im Frontalhirn während der Pubertätsphase ist vor allem für die Herausbildung von Charaktereigenschaften, für die Triebkontrolle und den Belohnungsaufschub sowie für die Entstehung von Moral und Wertehaltung wichtig.

Herpertz und Buchheim (2011) sind der Meinung, dass im Sinne der Prävention in Zukunft neurobiologische Prädiktoren zu identifizieren sind, die das psychopathologische Erscheinungsbild im Erwachsenenalter vorhersagen können und damit frühzeitig zu Hilfs- und Therapiemaßnahmen Anlass geben. Durch die Beschäftigung mit Hirnläsionen wurde früh die Bedeutung des präfrontalen Cortex bei der Entstehung sozial inadäquaten und impulsiven Verhaltens erkannt. Insbesondere eine Dysfunktion des neuronalen Netzwerks zwischen orbitofrontalem Cortex und Amygdala scheint mit Impulsivität und Aggressivität verbunden zu sein.

Casey et al. (2008) und Siever (2008) versuchen in ihren neurobiologischen Modellen zu erklären, wie die Zunahme des Risikoverhaltens Jugendlicher mit ihrer Bereitschaft auf Belohnungen zu reagieren, zusammenhängt. Die Zunahme des Risikoverhaltens scheint auch auf eine Unreife in der Verhaltens- 
kontrolle und auf eine Neigung, schnelle Erfolge statt langfristiger Ziele zu suchen, in Verbindung zu stehen.

Ein noch unreifer ventraler präfrontaler Cortex kann nach Ansicht von Casey et al. (2008) und Siever (2008) keine ausreichende „Top-down-Kontrolle“ der Affekte und der Belohnung versprechenden Region des Nucleus accumbens übernehmen. Impulsive Aggressionen können aufgrund eines Ungleichgewichts der „Top-down-Kontrolle“, die durch den orbitofrontalen Cortex (OFC) und den anterioren Cortex cinguli (ACC) sichergestellt wird, entstehen. Diese beiden Strukturen sind an der Anpassung des Verhaltens an soziale Gegebenheiten entscheidend beteiligt und ermöglichen dem Individuum, die erwarteten Konsequenzen in Form von Belohnung oder Bestrafung in seinen Entscheidungsprozess einzubeziehen.

Auf der anderen Seite kann eine verstärkte oder verminderte „Bottom-up“-Aktivierung limbischer Strukturen wie der Amygdala zu einer Dysbalance im Verhalten beitragen. Im lateralen Kern der Amygdala werden Signale und Informationen über bedrohliches Verhalten Dritter verarbeitet wie starrer Blickkontakt, bedrohliche Stimmen oder Gesten.

Casey et al. (2008) und Siever (2008) vertreten eine Hypothese, dass die Interaktion zwischen den die „Top-down“-Kontrolle gewährleistenden präfrontalen Regionen und die modulierende „Bottom-u“"-Signale sendenden limbischen Areale bei Patienten mit einer ,antisozialen Persönlichkeit“ gestört ist. Diese Patienten sind deshalb auch unfähig, aus negativen Erfahrungen zu lernen und negative Sanktionen zu antizipieren.

Bei Patienten mit einer „antisozialen Persönlichkeit“ wurde mit Hilfe des fMRT ein durchschnittlich um 11\% verkleinertes Volumen der grauen Substanz im präfrontalen Cortex gefunden. Außerdem wurden Veränderungen im orbitofrontalen Cortex, in Amygdala und Hippocampus festgestellt. Dies sind Hinweise auf ein „strukturelles“ Gehirndefizit, ohne dass eine äußerlich erkennbare Verletzung des Gehirns vorliegt.

Der präfrontale Cortex spielt eine wichtige Rolle bei der Konditionierung durch Furcht, die wiederum mit einer schwachen Entwicklung des Gewissens verbunden ist. Wer in der Kindheit nicht auf Kritik und erzieherische Strafen anspricht, neigt deshalb später zu ,antisozialem“ Verhalten. Daneben ist der präfrontale Cortex bei der Regulierung eines Erregungszustandes beteiligt. Schwache Erregungsniveaus des autonomen und zentralen Nervensystems bei antisozialen Personen motivieren diese dazu, starke Reize aufzusuchen (sensation seeking) und mit antisozialem Verhalten zu regulieren, um ihre mangelnde Erregung zu kompensieren.

Diese Befunde konnten mittels des fMRT bei männlichen Kindern und Jugendlichen im Alter von 8 und 15 Jahren mit Störungen des Sozialverhaltens durch Vloet et al. (2008) ebenfalls festgestellt werden. Unterstützt wurden die Ergeb- 
nisse durch vorherige Messungen der autonomen Reagibilität. Bei der Betrachtung von Bildern mit erschreckendem Inhalt wurden die Herzfrequenz, die Hautleitfähigkeit und das Augenblinzeln gemessen. Die Kinder und Jugendlichen, die eine Störung des Sozialverhaltens aufwiesen, zeigten eine verminderte Angstreaktion.

Die Möglichkeit, die emotionalen Reaktionen des anderen zu verstehen, ist an ein bestimmtes Ensemble von Hirnbereichen gebunden, die sich durch „Spiegeleigenschaften“ auszeichnen, was für die Entwicklung von Empathie und für den Umgang mit Feedback und Kritik bedeutsam ist (Rizzolatti und Sinigaglia 2008). Dieses „Spiegelneuronensystem“ zeigt, wie tief verwurzelt und stark die Beziehung ist, die uns mit den anderen Menschen verbindet, oder wie unmöglich es ist, sich ein „Ich ohne ein Wir“ vorzustellen.

Das Modell von Siever (2008) integriert auch die Bedeutung des serotonergen Transmittersystems bei aggressivem Verhalten, da der orbitofrontale Cortex zahlreiche serotonerge Projektionen enthält. Eine Dysregulation des serotonergen Systems kann indirekt zu einer Disinhibition von impulsiver Aggression führen. Ein niedriger Serotoninspiegel bringt Emotionen wie Bedrohungsgefühle oder Angst mit sich. Eine verminderte Erregbarkeit des Serotoninsystems setzt auch die emotionale Erregbarkeit herab. Beide Prozesse können sich auf aggressives Handeln auswirken.

Ein Zusammenhang zwischen einer Genvariante des Nitridoxid-Aufbauenzyms (Nitridoxidsynthetase) und Eigenschaften wie Impulsivität, Aggressivität und Hyperaktivität wurde von Reif et al. (2009) belegt. Nitridoxid ist ein „unkonventioneller“ Neurotransmitter, der an der Regulierung sexuellen wie auch aggressiv-impulsiven Verhaltens beteiligt ist (Staniloiu und Markowitsch 2011).

Auch andere Systeme wie das Dopaminsystem oder das GABAerge System ist in die Pathogenese von Wut, Impulsivität und Aggression involviert. Modulatoren der GABA-A-Rezeptoren wie Benzodiazepine oder Antikonvulsiva wie Valproat beeinflussen die Aggressivität. Eine intakte dopaminerge Aktivität in mesocortikolimbischen Regionen ist für die Initiierung und Ausführung aggressiven Verhaltens entscheidend.

Mithilfe bildgebender Verfahren wurden die verschiedenen Erkrankungen mit ausgeprägter impulsiver Aggression untersucht.

\section{Erkrankungen mit ausgeprägter impulsiver Aggression}

- Bei männlichen Patienten im Alter von 12-17 Jahren und einer Störung des Sozialverhaltens konnte als Reaktion auf emotionale Bilder eine stärkere Amygdala-Aktivität als bei gleichaltrigen Gesunden ermittelt werden (Herpertz et al., Sterzer et al. 2007).

- Bei der „antisozialen Persönlichkeitsstörung“ fanden sich reduzierte Volumina der grauen Substanz im präfrontalen Cortex. 
- Bei der „Borderline-Persönlichkeitsstörung“ wurden reduzierte Volumina des orbitofrontalen Cortex, des Cortex cinguli, des Hippocampus und der Amygdala festgestellt.

- Reduzierte Volumina des Hippocampus wurden auch bei Frauen mit frühen Misshandlungen in ihrer Vorgeschichte und bei Patienten mit einer PTBS gefunden.

- Bei Patienten mit einer Schizophrenie, einer unipolaren Depression oder bei einer bipolaren Störung und bei Patienten mit Zwangsstörungen wurden reduzierte Volumina des Hippocampus oder der Amygdala festgestellt.

Goodyer und Fairchild (2011) fanden bei dissozialen und aggressiven Jugendlichen eine verminderte Aktivität in der Amygdala und Insel im orbitofrontalen Cortex und in medialen präfrontalen Strukturen, die ihre geringe Ängstlichkeit und Empathiefähigkeit, Emotionslosigkeit und autonome Hyporeagibilität erklären könnte. Auch die Schmerzzentren des Gehirns reagieren, wenn Menschen sozial ausgegrenzt, zurückgewiesen, verachtet und gedemütigt werden. Nicht nur körperlicher Schmerz, sondern auch Ausgrenzung stellen „potente Reize dar, die den neurobiologischen Aggressionsapparat aktivieren und Gewalt hervorrufen können“ (Eisenberger, zit. nach Bauer 2011). Gesunde Individuen sind in der Lage, auf Schlüsselreize, wie ängstliche und ärgerliche Gesichter oder Stimmen, ihr eigenes Verhalten zu modifizieren und auch zu inhibieren. $\mathrm{Ob}$ diese neuen neurobiologischen Ergebnisse in der Zukunft diagnostisch als auch strafrechtlich bei der Beurteilung der partiellen Schuldunfähigkeit nach \ 21 StGB) verwertbar oder aussagekräftig genug sind, muss nach Meinung von Herpertz und Buchheim (2011) zum jetzigen Zeitpunkt offen bleiben.

\subsubsection{Gewalt aus soziologischer Sicht}

Das Thema „Gewalt und Aggression“ unter Schülerinnen und Schülern ist in den letzten Jahren immer mehr ins Zentrum der soziologischen Diskussion gerückt. Die wissenschaftliche Untersuchung dieses Phänomens begann in den frühen 1970er-Jahren in Skandinavien (Olweus 1992).

In seiner Studie zu Gewaltkarrieren von jugendlichen Tätern kommt Sutterlüty (2002) zu dem Ergebnis, dass vor allem eigene Gewalterfahrungen in der Kindheit sowie mangelnde soziale Anerkennung als Ursachen für späteres gewalttätiges Handeln gelten können. Jugendliche, die eine ohnmächtige Stellung im familiären Gewaltzusammenhang innehatten, deuteten es als einen „positiven Wendepunkt“ in ihrem Leben, wenn sie selbst zur Gewalt greifen und von der „Opferrolle“ in die „Täterrolle“ wechseln. Dieser Rollentausch kann in eine Dynamik münden, in der die Gewalt den „Charakter eines Selbstzwecks“ gewinnt. So stößt man in den Schilderungen der Jugendlichen immer wieder darauf, dass sie mit ihren Gewalthandlungen einen unmittelbaren subjektiven Gewinn verbinden, der in der Erfahrung einer faszinierenden „Intensität 
von Macht“ besteht. Das „euphorisierende Erlebnis“ der Gewaltausübung selbst wird zum treibenden Handlungsmotiv, das sich verselbstständigen kann. Dies setzt eine „Spirale der Wiederholung“ in Gang - nicht zuletzt auch deswegen, weil die beschriebenen Wirkungen der Gewalt immer nur von kurzer Dauer sind.

Aus soziologischer Sicht wird die Entstehung von Gewalt und Aggression anhand verschiedener Modelle mit unterschiedlichen Risikofaktoren erklärt. Insgesamt geht die soziologische Forschung von einem multikausalen Bedingungsgefüge aus, also von einem Zusammenspiel gesellschaftlicher, interpersoneller und intrapersoneller Faktoren.

In der heutigen Zeit lässt die „entfesselte Werbung“ (Baudrillard 1992) insbesondere dissoziale Jugendlichen glauben, sich das nehmen zu können, was ihnen zusteht, zumal die großen „Vorbilder“ der Gesellschaft - wie Politiker und Banker - dies ihrer Meinung nach in noch größerem Maßstab tun. Die mediale „Überstimulation“ und Überreizung im Zusammenspiel mit erlebter Langeweile ist eng mit dem Problem der Aggressivität und Destruktivität verbunden (Fromm 1996).

Zwei miteinander verzahnte Themen stehen im Mittelpunkt der aktuellen soziologischen Debatte (Luig 2010). Es gibt eine Auseinandersetzung darüber, „was“ Gewalt ist und „wie“ sie beschrieben werden kann; zum anderen gibt es Überlegungen darüber, wie Gewalt „erinnert“ und wie sie „verarbeitet“ wird.

Mitarbeiter des Hamburger Instituts für Sozialforschung üben Kritik an einen ihrer Meinung nach „überkommenen“ Gewaltbegriff, der sich überwiegend mit Ursachen oder Konsequenzen unterschiedlicher Gewaltanwendungen befasst. Sie fordern, sich mehr mit den „Aspekten extremer Gewalt“ zu befassen. Im Mittelpunkt ihres Interesses stehen Beschreibung und Analyse konkreter Gewaltereignisse im Gegensatz zu den eher abstrakten Analysen struktureller Gewalt. Im Vordergrund sollen ihrer Meinung nach die physische Gewalt und die bewusste Intention des Verletzens stehen.

Nach Reemtsma (2003, 2008a), ist Verzicht auf Gewalt das „entscheidende Moment“ der „gesellschaftlichen Kohäsion“ in der Moderne, sonst droht der Verlust des „sozialen Vertrauens“. Menschen handeln seiner Meinung nach nie einfach instrumentell, stets ist ein „existenzielles“ Moment im Spiel. Jede Tat ist dann auch eine Auskunft über den Täter und zeigt, wer er selbst ist und wer er sein will. Jede menschliche Handlung hat somit auch einen „kommunikativen Aspekt“.

Reemtsma (2008a) schlägt vor, drei Formen physischer Gewalt phänomenologisch nach ihrem Körperbezug zu unterscheiden:

1. Lozierende Gewalt. Sie behandelt den Körper des anderen als „Masse“, der ein Ort zugewiesen wird. Sie richtet sich nicht auf den Körper als solchen, sondern auf den „Körper als verschiebbare Masse“.

2. Raptive Gewalt. Sie benutzt den Körper, um an ihm irgendwelche, meist sexuelle, Handlungen zu vollziehen. 
3. Autotelische Gewalt. Sie will - wie beim Amok und School Shooting - den Körper beschädigen oder zerstören. Sie zielt auf eine bewusste „Zerstörung der Integrität“ des Körpers.

Diese Differenzierung des Gewaltbegriffs führte dazu, dass das Zufügen wie das Erleiden körperlicher Verletzungen in den Mittelpunkt der neuen Gewaltsoziologie rückte. Für einen Gewalttäter ist die größte Macht, andere Körper nach Willkür zu zerstören. Von einigen Jugendlichen, bei denen es im Verlauf von Schlägereien zu massiven aggressiven Impulsdurchbrüchen gekommen ist, wird ein regelrechter „Blutrausch“ mit absolutem Kontrollverlust und „Blackout-Situationen" beschrieben.

„Lozierende, raptive und autotelische Gewalt“ haben je eine andere „teleologische“ Beschaffenheit. Autotelische Gewalt verstört die Menschen am meisten, die sich dem Verständnis und dem Erklären weitestgehend zu entziehen scheinen.

\begin{abstract}
Der Attentäter der Anschläge von Norwegen (22.07.2011) A. B. Breivik tötete in zwei aufeinanderfolgenden Anschlägen 76 Menschen. Er äußerte nach seiner Verhaftung, er habe der sozialdemokratischen Partei Norwegens größtmöglichen Schaden durch Tötung der zukünftigen Partei-Elite zufügen und ein „kräftiges Signal“ an das norwegische Volk geben wollen. Der Täter benutzte bei seinem Massaker Dum-dum-Geschosse, die im Körper zersplittern und besonders schwere Verletzung verursachen. In seinem 1.500-seitigen Manifest kündigte er an, dass er „minderwertiges Leben mit Kugeln abschießen“ werde. (Süddt. Zeitung vom 26.07.2011).
\end{abstract}

Unsere westlich geprägte Kultur hat gravierende Probleme, insbesondere mit dem „Phänomen der autotelischen Gewalt“ umzugehen, wie sie auch heutzutage von islamistischen Selbstmordattentätern ausgeführt wird. Nach Reemtsma (2008a) bewirkt diese Gewaltform einen besonders großen Schrecken, weil sie nach unserem rationalen Verständnis nicht einem „Kosten-Nutzen-Kalkül“ unterworfen werden kann. Wo „instrumentelle Deutung“ versagt, greifen wir zur „Pathologisierung und zur Verrätselung“. Der Täter zerstört die Körper, weil er „Macht“ dazu hatte. Diesen „Zusammenhang von Macht und Gewalt" haben wir nach Reemtsma in der Moderne geächtet und verlernt, ihn wahrzunehmen. Menschen, die Fähigkeit haben, über ein Zerstörungspotenzial zu verfügen, haben seiner Meinung nach die größte Macht, die einem Menschen gegeben werden kann, nämlich andere Körper nach Willkür zu zerstören.

Das Schweigen der soziologisch orientierten Wissenschaftler zum Problem der Gewalt ist nach Reemtsma (2008a) Teil einer Verdrängungsstrategie (CopingStrategie) der Moderne, die dazu neigt, Gewalt eher instrumentell und als „lozierende Gewalt“, aber nicht als autotelische Gewalt zu verstehen. Die autotelische Gewalt wird dann „ausgegrenzt“ und als pathologisch angesehen und ,verrätselt“. Für solches pathologisches und rätselhaftes Verhalten sind dann nur 
noch Spezialisten für abweichendes Verhalten wie Kriminologen, Profiler und Psychiater zuständig. So setzt sich Reemtsma (2003, 2008a) mit den üblichen Wahrnehmungs- und Deutungsmustern von Gewalt auseinander und versucht durch seine Art der Betrachtung, die „blinden Flecken“ der Moderne in den Blick zu nehmen.

Reemtsma (2008b) setzte sich mit der „Theorie des kommunikativen Handelns“ (Habermas 1981), die auf eine allgemeine Gesellschaftstheorie zielt, auseinander und unterstellt ihm in der Gewaltdiskussion ,theoretische Blindheit“. Dieser bisherigen Interpretation der Cewalt als instrumentell, pathologisch und sinnlos setzt er das „Konzept der selbstzweckhaften Gewalt“ - autotelischen Gewalt - entgegen, die auf die Zerstörung des Körpers des Opfers aus ist und in der sich der Wunsch nach absoluter Macht erfüllt.

Der französische Philosoph Bataille (1995, zit. nach Wiechens) setzte sich schon vor einigen Jahrzehnten mit der damals schon immer dringlicher werdenden Problematik von „sinnlosen Gewalthandlungen“ auseinander. Seiner Meinung nach manifestiert sich für ihn in der „Grenzüberschreitung“ durch den Gewaltakt einerseits eine „Auflösung des Subjekts, Zersplitterung des Selbst, der Identität und seiner Bindung“, andererseits aber auch paradoxerweise eine „Wiedereinführung des Subjekts“: „Indem ich meine Grenzen überschreite, bin ich“.

Grenzerfahrungen und Grenzüberschreitungen sind Teil der individuellen Erfahrungen im Verlauf der normalen Pubertät.

Bataille (1995) drückt aus, dass der Mensch seine volle Unabhängigkeit und Souveränität erst im bewussten Übertreten des Verbotes in gefährlichen, risikoreichen Augenblicken und im „Aufs-Spiel-Setzen“ wie im „Verschwenden des eigenen Lebens“ erwirbt. Man kann nur staunen, wie genau Bateille schon vor einigen Jahrzehnten wesentliche Aspekte des Täterprofils von Menschen, die heute Massaker ausführen, erkannte und vorwegnahm. Bataille entdeckte sogar in den „Erfahrungen von Schmerz und Leiden“ eine „Dimension der Befreiung“. Indem der Gewalttäter seine Distanz zu seinem Körper aufhebt, verschmilzt er auf eine „animalische“ Weise mit ihm und wird selbst „ganz Körper“. Die im Zentrum der Theorie von Bataille (1995) stehende ambivalente Erfahrung der Grenzüberschreitung ist zwischen Angst und Entsetzen und intensivem Verlangen und Lust angesiedelt. Bataille setzte sich auch intensiv mit dem ,verfemten Teil“, dem nicht akzeptierten destruktiven Teil einer Person, auseinander.

Das „Ausgeschlossene“ und das „Verfemte“ muss ins eigene Blickfeld geraten, damit es integriert wirkungslos wird (Bataille 1995, zit. nach Wiechens). 
Auch für Baudrillard (1992) ist der Ausgangspunkt seiner Überlegungen zum Prinzip des „Bösen“ das „Theorem des verfemten Teils“, worunter er die Annahme der „Unzertrennlichkeit von Cut und Böse“ versteht, deren Ausprägungen, obwohl unversöhnlich, dennoch beide aufeinander angewiesen bleiben. Baudrillard schrieb: „Wer seinen verfemten Teil ausmerzt, besiegelt seinen eigenen Tod“. Ohne seinen ,verfemten Teil “ ist das Gute kraftlos.

Die Sichtweise von Bataille (1995, zit. nach Wiechens) und Baudrillard (1992) hat den Vorteil, die Aufmerksamkeit auf eine von anderen eher vernachlässigte Dimension gelenkt zu haben, nämlich die unerklärliche, „mysteriöse“ Gewaltbereitschaft und Gewaltakzeptanz ins Blickfeld gerückt zu haben, ein Aspekt, der erst Jahrzehnte später wieder von Reemtsma (2008a) aufgegriffen wurde.

Mit dem Begriff der "Grenzüberschreitung“ schärften Bataille (1995) und Baudrillard (1992) das Bewusstsein für die meist nicht eingestandene, aber stets die Person des Täters affizierende, „rauschhafte“, willkürliche und faszinierende Seite von Gewalthandlungen. „Die Zukunft verschwindet in intensiv erlebter Cegenwart“. Körper und Geist werden in der Gewalthandlung in vollster Aktivität und Handlungseinheit erfahren.

Nach Sorg (2011) begleitet das „Böse“ seit jeher die Geschichte der Menschheit. Seiner Meinung nach ist es sogar die „Bedingung der menschlichen Freiheit“. So sehr es lähmende Angst verursacht, so sehr lockt das Böse mit verführerischen Angeboten. Es unterbricht die „Monotonie des Alltags, bedeutet Spannung und Intensität, verspricht die Befreiung von Zwängen und Grenzen“. Die bewusste, illusionslose und bis zu einem gewissen Grad auch unerschrockene Zuwendung zu Gewalt und Tod enthält implizit die Forderung, dass ,wir permanent mit dem Gewaltpotenzial in uns rechnen und uns niemals der Illusion hingeben, wir seien vor dem Durchbrechen destruktiver Impulse gefeit“.

Dabei geht es Bataille (1995, zit. nach Wiechens) nicht um eine „Dämonisierung“ dieser psychischen Kräfte, sondern einzig darum, dass wir stets für diese Dimension "hellhörig“ bleiben. Außerdem verweist Bataille darauf, dass wir Menschen das „Aggressionspotenzial in uns“, wenn wir es wirklich ernst nehmen und es weder ängstlich aus unserem Erleben ausblenden noch bagatellisierend darüber hinweggehen, zumindest zu großen Teilen in konstruktive Bahnen lenken können. Diese Integrationsarbeit gilt es mit potenziellen Tätern zu führen.

Auch Lévinas (1991) analysierte Kommunikationen unter dem Blickwinkel riskanter Entgrenzungen. Kommunikationen finden seiner Meinung nach nur dann statt, wenn die daran

„Beteiligten sich bis zu einem gewissen Maße selbst aufs Spiel setzen und auf ihre eigene Unversehrtheit in bewusster Weise verzichten“.

Alle, die in eine Beziehung mit anderen Menschen eintreten, „öffnen sich dem anderen, und stellen sich dadurch auch bloß." Bei einer gelungenen Kommunikation 
kann das Individuum seine bis dahin behauptete Eigenständigkeit verlieren im Sinne eines „Verschmelzungserlebnisses “ in einen qualitativ völlig ,verschiedenartigen Seinsbereich “ der Verständigung, der Verbundenheit und der Kontinuität eintauchen.

Durch die enge Verquickung von Gewalt, Körper- und Schmerzerfahrung eröffnen sich neue Fragen nach dem Erleben und nach der Erinnerung von Gewalt, wie etwa Gewalt in den Körper „eingeschrieben“ wird, in welcher Weise man sie erinnert und wie darüber gesprochen oder geschwiegen wird. Weitere Fragen sind, welche Metaphern für diese Erfahrungen und Erinnerungen verwendet und wie sie mit der Wahrnehmung der eigenen Identität verknüpft werden. Wenn man entsprechende Situationen schafft oder vorfindet, wo „autotelische Gewalt" (Reemtsma 2008a) ausgeübt werden kann, wird sie schließlich auch ausgeübt werden. Das gilt auch für Jugendliche, die vor oder nach der Tat pathologische Auffälligkeiten gezeigt haben.

Kleinman et al. (1997) haben den Begriff des „social suffering“ geprägt, der die Durchdringung von individuellen Lebenserfahrungen mit den destruktiven „Folgen von Macht und Herrschaft" in den Blick nimmt. Die entscheidende Frage ist, wie die Gewaltexzesse der Moderne, die Zivilisationsbrüche des zo. Jahrhunderts, in die heutige Gesellschaft - durch konstruktivere Auseinandersetzungsformen in Familien -, mit den schon entstandenen über Generationen tradierten Mustern integriert werden können. Hierzu zählt die Verarbeitung der Kriegstraumata der Großeltern- und Elterngeneration.

\subsubsection{Besonderheiten destruktiver Gewalt bei Gang-Bildung}

Schul-Amoktäter sind in der Regel Einzeltäter. Der „Lone-Wolf“-Philosophie verschrieben sie sich jedoch oft erst nach Jahren, weil sie sich von außen nicht beeinflussen lassen und ihre Tat lieber im Alleingang durchführen wollten.

Die Suche nach Nähe zu verhaltensauffälligen Gleichaltrigen in Peer-Gruppen ist ein starker Hinweis für Verhaltensstörungen. In diesen Gruppen teilen sie miteinander ihr gemeinsames Schicksal, ihre emotionalen Wunden mit einer gegenseitigen „narzisstischen Spiegelung " und Idealisierung. Gemeinsam versuchen sie, ihr angeschlagenes Selbstwertgefühl durch „gemeinsame Fantasien von Macht und Gewalt " zu stabilisieren. Jugendliche mit schweren Verhaltensstörungen neigen zur positiven Einstellung gegenüber kriminellem Verhalten und zu Personen, denen sie feindselige Einstellungen und Absichten unterstellen. In diesen Peer-Gruppen entwickeln die Jugendlichen Vorstellungen von „hegemonialer Männlichkeit“, vor allem wenn sie sich selbst bedroht oder erniedrigt fühlen. Ihre nach außen nicht gezeigte Ohnmacht schlägt dann in Wut um. Gewalt ist dann für sie ihre „letzte Option“, ihre „Männlichkeit“ wiederherzustellen. Es kommt zu einer „Etablierung eigener Ceset$z e$ “ und Umdeutung der alltäglichen Realität. Ihrer Meinung nach haben sie 
nicht ,versagt“, vielmehr sehen sie sich ,in ihren besonderen Fähigkeiten verkannt“. Beziehungen außerhalb der Peer-Gruppe werden oft abgebrochen. Innerhalb der Gruppe entwickeln sie ein „Wir-Gefühl“ durch „Gleichschaltung“ von Gedankengut. Sie bestätigen sich gegenseitig Größenfantasien oder durch Vorstellungen, die wahren Auserwählten und Retter zu sein. Dies drückt sich dann auch in ihrer uniformierten Kleidung aus. In Gewaltinszenierungen versuchen sie, traumatische Erfahrungen von Gewalt im Sinne eines Wiederholungszwangs zu wiederholen.

Auch bei Mädchen besteht eine Tendenz zur Gewaltbereitschaft. Bisher war man immer davon ausgegangen, dass Mädchen eher „Mitläufer“ wären oder sich ihre Aggressivität auf „Haare ziehen und Aufhetzen“ beschränke. Es kommt jedoch zunehmend zu Gewalttätigkeiten wie Zuschlagen und Treten. Als Grund für diese Entwicklung nimmt man ein Ähnlicherwerden der Lebenssituationen von Mädchen und Jungen an. Auch in anderen Verhaltensweisen gleichen sie sich einander an. Wie Jungen bilden nun auch Mädchen Gruppen, in denen sie Anerkennung durch gemeinsame Gewaltausübung zu bekommen suchen.

\subsubsection{Die Bedeutung und Einflüsse neuer Medien}

„Die Art des Mediums bestimmt die Art der Botschaft“ (The medium is the message).

Diese These stellte der Kommunikationstheoretiker Marshall McLuhan schon 1967 auf. Dies gilt auch für alle Massaker, damit auch für Schul-Amoktaten. Medien werden von potenziellen Tätern heute verstärkt benutzt, um Angst und Schrecken zu verbreiten. Sie inszenieren verschiedene Arten von „Stilisierungen und Heroisierungen“ (Drobinski 2011), um Nachahmer und Aufmerksamkeit für ihre Motive zu finden.

„Das Netz bietet unendliche Freiheit und Toleranz, aber eben auch die Einengung und die Spirale des von allen sozialen Filtern befreiten Hasses."

Potenzielle Täter, die sich aus dem Internet mit radikalen Informationen versorgen, sind mit den bisherigen Methoden der Sicherheitsbehörden schwer auszumachen und deshalb auch nur schwer zu bekämpfen.

Die Medien problematisieren in zunehmendem Maße Computerspiele mit realitätsnahen Gewaltdarstellungen und Tötungsszenen. Nach dem Amoklauf von Erfurt gerieten insbesondere diese Spiele in die Kritik, weil sich der Täter R. Steinhäuser intensiv vor seiner Tat mit dem Ego-Shooter-Spiel „Counter Strike “ beschäftigt hatte. Seitdem wollen Kriminologen, dass die Prävention gegen Gewalt verstärkt im Internet beginnen soll.

Die Netzwelt kann „keine rechtsfreie Parallelwelt ohne Verbotsschilder" sein (Leipziger Volkszeitung 25.7.2011) 
Georg R., der Schul-Amokläufer von Ansbach (2009), begann ein halbes Jahr vor seiner Tat ein Tagebuch an „Summer" zu schreiben, eine amerikanische Schauspielerin. Sie stellte in einer Fernsehserie eine Art Roboter dar und interessierte sich für "ungewöhnliche Typen“. Georg R. dachte, sie würde sich vielleicht auch für inn interessieren.

Die politische Debatte um Gewalt-verherrlichende Computer- und Videospiele führte im Jahr 2003 zu einer Verschärfung des Jugendschutzrechts. „Killerspiele“, in denen zum Selbstzweck Mordszenen dargestellt werden, können auf den Index für jugendgefährdende Medien gesetzt werden. Sie dürfen dann weder öffentlich ausgestellt noch beworben werden. Im Jahr 2008 machte die Bundesprüfstelle bei 43 Spielen davon Gebrauch, indem sie 169 Videos und 265 Online-Angebote auf den Index setzte. Zugleich versucht man, Jugendliche durch eine bessere und deutlichere Altersklassifizierung vor nicht altersgerechten Spielen zu schützen. Für das Angebot von Spielen ohne Jugendfreigabe gilt das gleiche wie für Alkoholausgabe: Sie dürfen nur gegen Vorlage des Ausweises abgegeben werden.

Die Beschäftigung mit gewalthaltigen Medien und deren Auswirkungen sorgt in der öffentlichen Diskussion nach Mikos (2009) allzu oft für eine „verkürzte Kausalitätsdiskussion“. Die Medien werden gern unter „Pauschalverdacht“ gestellt und als „Sündenbock“ missbraucht, um von den realen sozialen Ursachen abzulenken, die in der Familie, Schule oder Beruf sowie in den Peer-Gruppen der Jugendlichen liegen (Mikos 2009).

Heitmeyer (2009) nennt dies eine „Umdeutungsfalle“, bei der Gewalt „personalisiert, pathologisiert oder gar biologisiert" wird, weil damit von allen sozialen Ursachen und Zusammenhängen abgesehen und eine moralische Selbstentlastung sowie eine politische Erleichterung von Herrschenden betrieben wird, die repressiven administrativen Maßnahmen wie Implementierung eines neuen Waffengesetzes Vorschub leisten würden. Nach Heitmeyer (2009) stellen „Medien, wie Computerspiele, höchstens Verhaltensmuster und Verhaltensstrategien bereit, aber nicht die Entscheidung zur Tat“.

Meloy et al. (2001) entwickelten fünf Kriterien zur Einschätzung des Einflusses der neuen Medien

\section{Kriterien zur Einschätzung des Einflusses der Medien}

- Themenkonsistenz (theme consistency)

- Szenenspezifität (scene specifity)

- Wiederholtes Betrachten (repetitive viewing)

- Selbstbearbeitung (self-editing)

- Eintauchen in Aggression (aggression immersion) 
Themenkonsistenz meint, dass die Gedankenmuster, Gefühle oder Verhalten des Täters mit denen des Gewalttäters im Film und seiner Rolle übereinstimmen. Der potenzielle Täter identifiziert sich mit bestimmten Motiven des Gewaltvideos.

Szenenspezifität bedeutet, dass der potenzielle Täter bestimmte Wörter, Gesten, Kleidung oder Verhalten des Vorbilds vor und während der Durchführung des Verbrechens imitiert. Er stellt spezifische Szenen nach und nimmt sie auf Video, Handyvideo usw. auf.

Wiederholtes Betrachten verweist darauf, dass sich der potenzielle Täter die ihn erregenden Szenen immer wieder anschaut. Nach Meloy et al. (2001) wirkt sich die „Bildschirmgewalt“ umso stärker aus, je unmittelbarer sie vor den Taten konsumiert wird.

Selbstbearbeitung bedeutet, dass die potenziellen Täter Gewaltvideos in unterschiedlichen „Modi“ ansehen, wie in Zeitlupe. Gewaltszenen werden dann zusammengeschnitten und modifiziert und aus dem erzählerischen Kontext genommen, als hätten sie keine „moralische Signifikanz“ mehr.

Diese vier Begriffe beschreiben einen „kumulativen Prozess“ zu immer höherer Intensität der Aggression. Es findet eine absichtliche Stimulation und ein „Eintauchen in Aggression“ (aggression immersion) statt, um in eine gewalttätige Stimmung zu kommen, wobei die immer besseren Darstellungsmöglichkeiten zusätzlich eine höhere Identifikation ermöglichen.

Grimm (1999) entwickelte einen „kognitiv-physiologischen Ansatz“, um den Zusammenhang von Mediengewalt und Gewalthandlungen in der sozialen Realität zu untersuchen. Dabei zeigte sich, dass sich eine kurzfristig gesteigerte Aggressivität bildet, die dann wieder verebbt.

Die Fallbeispiele von W. Huck machen deutlich, wie sich Jugendliche in krisenhaften Zuspitzungen ihr Aggressionspotenzial dadurch steigern, indem sie sich durch „Ballerspiele“ regelrecht „anheizen“. Die Wirkungen hängen von der „Art der dramaturgischen und ästhetischen Inszenierung der Mediengewalt" ab (Grimm 1999). Jugendliche lernen mit Hilfe ihrer Handy-Videos beim „Happy Slappy“, dass man sich durch Gewaltausübung bekannt und interessant machen kann, indem sie bewusst die Medien als Verstärker und zur Verbreitung ihrer „Botschaften“ nutzen.

\subsubsection{Wie wirken die Medien auf potenzielle Täter?}

„Call of duty: Modern Warfare 2“ ist eine aktuelle Kriegssimulation, die den Spieler als Mitglied einer multinationalen Task Force in verschiedene Einsatzgebiete führt. Der Attentäter von Norwegen, Breivik, empfahl diese moderne Kriegssimulation ausdrücklich als „Schießübung für urbane Europäer“, die Schwierigkeiten haben dürften, überall mit Waffen zu trainieren. 
Es deuten einige Anzeichen daraufhin, dass die späteren Täter gewalthaltige Medienprodukte auch zur Kompensation von Ohnmachtsgefühlen nutzten. Viele drehten vor ihrer Tat Videos, in denen sie sich als „,kaltblütige Killer“ oder „Rächer“ inszenierten. Bücher, Filme, PC-Spiele und Musik - dies alles kann Amokläufern und School Shootern als Vorlage für ihre Tat und als „Quelle der Inspiration" dienen.

Der unkontrollierte, stundenlange Konsum von „Ego-Shootern“ kann durch ihren „Ansteckungseffekt“ zu einem Verstärker von Gewaltexzessen werden. Die weitgespannten Online-Netzwerke sorgen für eine schnelle Kommunikation abwegiger oder negativer Gedanken und Impulse. Sie ermöglichen ein sofortiges Feedback. „Cyberkontakte“ ermöglichen neue Ausdrucksformen von destruktiven Fantasien, die sich schnell weltweit verbreiten, was für impulsive und für Gewalt empfängliche Jugendliche verhängnisvoll sein kann (Harnisch 2011). Dabei geht es nicht nur um das Besiegen, sondern um ein „Vernichten“. Es hat jedoch den Anschein, dass aggressive Computerspiele bei Amokläufern und School Shootern nicht häufiger vorkommen als bei anderen Jugendlichen.

Das grundlegende Steuerungsprinzip unseres westlichen Wirtschaftssystems setzt auf individuelle Leistung und Konkurrenz und fördert nach Keupp (2010) eine „Ich-zentrierte Vermarktung“ der Person. Gleichzeitig zieht seiner Meinung nach die „Ideologie des autonomen Subjekts“ durch die Geschichte der Moderne, indem sich Menschen alle Erfolge, aber auch Misserfolge als „selbstproduziert“ zurechnen. Die Täter ertragen weder die pluralistischen Lebensformen noch die eingetretenen Differenzierungsprozesse in der modernen Gesellschaft.

Andererseits gibt es auch Indikatoren für gegenläufige Entwicklungen, denn in einer konstruktiven Netzwerkarbeit steckt ein hohes „Potenzial für Solidarität und kommunitären Verknüpfungen“. In solchen solidarischen Netzen ist die Basis für die Überwindung eines „egozentrierten Individualismus“ angelegt, und es besteht somit die Chance für die „Produktion und Erprobung kommunitärer Individualität“ (Keupp 2010).

Nach Baudrillard (1992) befinden wir uns in einer Zeit „nach der Orgie“. Die „Orgie“ ist für ihn in der Moderne der „explosive Augenblick“, der „Augenblick der Befreiung“ in allen Bereichen: politische und sexuelle Befreiung, Befreiung der Frau, des Kindes, der unbewussten Triebe und der Kunst, Entfesselung der produktiven sowie der destruktiven Kräfte. Er stellt die Frage: „Gibt es noch Steigerungen?“ und beantwortet sie damit, dass wir im „Zustand der Simulation“ alle denkbaren Szenarien durchspielen können.

Die heutigen Menschen leben nach Baudrillard (1992) in einer

„grenzenlosen Vervielfältigung von Idealen, Phantasmen, Bildern und Träumen, die hinter uns liegen und die wir dennoch in einer schicksalhaften Gleichgültigkeit weiter produzieren müssen“. 
Die Medienbilder schweigen nie. Bilder und Botschaften folgen ohne Unterbrechung aufeinander. Die ganze Kommunikation ist im Grunde nur ein ,forciertes Szenario“, eine „ununterbrochene Fiktion des Bildschirms“, die die „Leere der Mattscheibe“ wettmacht, auch die unserer „mentalen Mattscheibe“.

In der heutigen Kinder- und Jugendliteratur ist nach Faulstich und Lippert (2001) Gewalt das Hauptphänomen, an dem sich seit den 199oer-Jahren das „Böse“ zeigt. Dabei bleibt das „Böse“ letztlich eine „unbegreifliche Faktizität“ (Kierkegaard, zit. nach Sorge 2011). In den Geschichten über Gewalttaten findet die psychische oder körperliche Gewalt meist unter Kindern und Jugendlichen statt. Es werden selten allgemeingesellschaftliche Gewaltverhältnisse dargestellt. Die Schulgemeinschaft, an der sich ein Amokläufer rächt, kann aber durchaus stellvertretend für die Gesellschaft im Allgemeinen stehen. Die meisten Kinder- und Jugendbücher, die Gewalterfahrungen thematisieren und deren Ursachen klären wollen, vermitteln den Eindruck, dass Gewalt kontrollierbar und zu verhindern sei. So wird in Morton Rhues (2000) „Ich knall euch $a b$ “ eine Geschichte erzählt, wie zwei Jugendliche zu Amokläufern wurden. Dabei werden alle Facetten wie Außenseitertum, Opfer von Mobbing, Scheidung der Eltern usw. dargestellt. Anhand von authentischen E-Mails und Chats wird diese Geschichte aus der Perspektive der erzählenden Stiefschwester eines der Täter rekonstruiert. Sie entschließt sich, vom Ort des Geschehens „erst wieder abzureisen, wenn ich verstanden habe, was sich dort abgespielt hat.“ (Rhue 2000).

\subsubsection{Die neuen Helden}

„Helden“ sind für die Auseinandersetzung von Kindern und Jugendlichen mit ihrem Selbstbild und ihrer sozialen Umwelt essenziell (Bohrer und Scheel 2009). Die Ambivalenz von Stärke und Schwäche, Größe und Kleinheit, von Allmacht und Ohnmacht, die sich in Heldenbildern widerspiegelt und von ihnen transportiert wird, gewinnt insbesondere in der Sozialisierung von Kindern zentrale Bedeutung. Kinder benötigen in besondere Weise Vorbilder und Orientierungshilfen. Sie verlangen dabei vor allem nach nicht angeleiteter Orientierung. Medialen Protagonisten bieten ihnen diese Vorbilder, die mit Schönheit, Humor und Stärke ausgestattet sind und ihnen für ihre Interessen und Belange attraktiv und funktional erscheinen. Die alten Helden starben noch auf den „Schlachtfeldern“. Sie zeigten keine Schwächen und konnten ihre Männlichkeit bis zum Äußersten treiben.

Die zahlreichen Nachahmungen von „Helden“ eröffnen im westlichen Kulturkreis neue Möglichkeiten, sich durch einen ,grandiosen Abgang " und durch eine „Verewigung im Internet“ für ihre Kultgemeinde „unsterblich“ zu machen und neue „Heldenmythen“ zu entwickeln. Durch ein Massaker soll die Mitwelt in Angst versetzt werden. Sie stilisieren sich zu „Märtyrern“ und hoffen, dass der Ort des Anschlags zu einer "Wallfahrtsstätte“ wird, um sich grenzenlos zu erhöhen. Die 
Aussicht, ein „besonderer“ und „einzigartiger“ Mensch zu werden, der nur von ebensolchen Menschen verstanden werden kann und der Wunsch, nur mit solchen Menschen Kontakt zu pflegen, führt jedoch meist zu einer zunehmenden sozialen Isolierung und verstärkt zusätzlich ihre Unfähigkeit, sich in die innere Welt anderer Menschen einzufühlen (Milch 2007).

Die „Versuchung zur Gottähnlichkeit, die Verlockung, den anderen zu erniedrigen oder gar auszulöschen, um die Schrankenlosigkeit der eigenen Macht auszukosten“, ist nach Sorg (2011) nicht das exklusive Problem des ,underdogs“, der auf „,Rache für seine Machtlosigkeit“ sinnt. Sie sei Teil der allgemeinen menschlichen Situation, die ,jeden Einzelnen immer wieder vor die moralische Wahl stellt, zwischen Maßlosigkeit seiner Begehren und den Forderungen der Zivilisation zu entscheiden“ Sorg (2011). Der Tod wird dann zum „willkommenen Reisekameraden“ (Kohtes 1994).

Einen Menschen, der sich durch Gewalttaten ein „Denkmal“ setzen will, nennt man „Herostraten-Typ“ (Prantl 2011).

Der Grieche Herostrat setzte im Jahr 356 v. Chr. den Artemis-Tempel in Ephesus in Brand, um unsterblichen Ruhm zu erringen und sich durch seine Tat in die Weltgeschichte „einzubrennen“. 